\title{
REGRESSION DISCONTINUITY AND THE PRICE EFFECTS OF STOCK MARKET INDEXING
}

Yen-cheng Chang Harrison Hong Inessa Liskovich

Working Paper 19290

http://www.nber.org/papers/w19290

\author{
NATIONAL BUREAU OF ECONOMIC RESEARCH \\ 1050 Massachusetts Avenue \\ Cambridge, MA 02138 \\ August 2013
}

The views expressed herein are those of the authors and do not necessarily reflect the views of the National Bureau of Economic Research. This draft is a substantially revised version of our SSRN manuscript entitled "Rules and Regression Discontinuities in Asset Markets" dated March 25, 2011. Hong acknowledges support from an NSF grant. We thank Jeffrey Kubik, Larry Harris, Pete Kyle, David Lee, Jeremy Stein and seminar participants and discussants at Seoul National University, Tulane University, University of Washington, 2012 WFA, CICF, FMA Asia, Fall 2011 NBER Behavioral Finance Meeting, Winter 2011 Princeton-Lausanne EPFL Conference, Fudan University, National Taiwan University and the Swedish Institute for Finance Research for very helpful comments. We also thank Russell Investments for providing data and $\mathrm{He} \mathrm{Ai}$ for her research assistance. The internet appendix is available online at http://www.princeton.edu/ hhong/rd2000appendix

NBER working papers are circulated for discussion and comment purposes. They have not been peerreviewed or been subject to the review by the NBER Board of Directors that accompanies official NBER publications.

(C) 2013 by Yen-cheng Chang, Harrison Hong, and Inessa Liskovich. All rights reserved. Short sections of text, not to exceed two paragraphs, may be quoted without explicit permission provided that full credit, including $(\mathcal{C}$ notice, is given to the source. 
Regression Discontinuity and the Price Effects of Stock Market Indexing Yen-cheng Chang, Harrison Hong, and Inessa Liskovich

NBER Working Paper No. 19290

August 2013, Revised October 2013

JEL No. G02,G12

\begin{abstract}
$\underline{\text { ABSTRACT }}$ for both additions and deletions.

Yen-cheng Chang

Shanghai Advanced Institute of Finance Shanghai Jiao Tong University

211 West Huaihai Road

Shanghai, China

ycchang@saif.sjtu.edu.cn

Harrison Hong

Department of Economics

Princeton University

26 Prospect Avenue

Princeton, NJ 08540

and NBER

hhong@princeton.edu

Inessa Liskovich

Department of Economics

Princeton University

Fisher Hall

Princeton, NJ 08544

iliskovi@princeton.edu
\end{abstract}

Studies find price increases for additions to the S\&P 500 index but no decreases for deletions. Additions come with good earnings news, suggesting these studies are not just measuring an indexing effect. We develop a regression discontinuity design using Russell Indices for cleaner identification. Stocks are assigned to indices based on their end-of-May market capitalizations. Stocks ranked just below 1000 are in the Russell 2000. The indices are value-weighted so these stocks receive index buying whereas those just above 1000 have close to none. Using this random assignment, we find price effects 


\section{Introduction}

We tackle a long-standing problem in the important literature on stock market indexing. Many studies find that stocks that get added to the Standard and Poor's (S\&P) 500 index, or other widely followed indices, experience a positive risk-adjusted return (see, e.g., Shleifer (1986), Harris and Gurel (1986)). For instance, the most famous of these, the S\&P 500 index addition effect, is around five to seven percent in the month following the addition announcement date and a large fraction of the price effect is permanent (see, e.g., Beneish and Whaley (1996), Lynch and Mendenhall (1997), Wurgler and Zhuravskaya (2002)).

The preferred interpretation of this finding is that the excess risk-adjusted return is due to forced buying by passive stock index funds and by many active institutional investors who are benchmarked to these indices. These studies suggest that the demand curves for stocks, even large ones such as those in the S\&P 500, are downward sloping. This is contrary to the central tenet of the efficient markets hypothesis, which asserts that stocks have many substitutes and hence their demand curves should be flat.

The traditional methodology assumes that added stocks differ from a control group of non-added stocks, typically just the market portfolio, only due to forced buying. However, a number of studies call into question the plausibility of this interpretation. First, Denis, McConnell, Ovtchinnikov, and Yu (2003) find that additions to the S\&P 500 are associated with an increase in earnings forecasts and improvements in realized earnings. Second, Chen, Noronha, and Singal (2004) find that stocks that get deleted, and every addition comes with a deletion, have no permanent negative price effect. If the observed positive price effect of addition is due to indexing or benchmarking by institutional investors, one should see a negative price effect for deletion when such demand is no longer necessary.

Instead, this asymmetric price reaction seems more consistent with a news event as argued by Denis, McConnell, Ovtchinnikov, and Yu (2003) or investor recognition (see, e.g., Merton (1987)), where the stocks that get added to the S\&P 500 index are subsequently recognized and have higher prices for a variety of reasons other than forced tracking. Another related 
mechanism is attention (see, e.g., Barber and Odean (2008) or Hirshleifer, Lim, and Teoh (2009)). Recognition or attention might plausibly not go away after deletion, as Chen, Noronha, and Singal (2004) rightly point out, which would then explain the asymmetric price pattern.

While the S\&P 500 studies are among the most insightful in financial economics, distinguishing between an indexing effect, news about fundamentals, or any alternative hypotheses such as the recognition hypothesis remains important. If existing findings are not cleanly identified as due to forced buying or tracking, but are instead correlated with other effects or news shocks that coincide with addition, then the challenge to the efficient markets view would be much weaker.

To solve this long-standing problem, we develop a new methodology, a set of regression discontinuity (RD) experiments associated with the Russell 2000 index, that can cleanly identify a forced tracking price effect. Stocks are ranked on the last trading day of May (i.e. end-of-May) based on their market capitalizations. The first 1000 are in the Russell 1000. The next 2000 are in the Russell 2000. The end-of-May market capitalization cutoffs lock in membership for an entire year. A stock that is in the Russell 2000 based on the end-of-May market capitalization stays in the 2000 index for an entire year even if its market capitalization subsequently grows and exceeds those of stocks in the Russell 1000. Similarly a stock in the Russell 1000 stays in the 1000 index for an entire year even if its market capitalization is subsequently lower than other stocks in the Russell 2000.

Since the indices are value-weighted, stocks with end-of-May market capitalizations just below the 1000 cut-off receive significant forced buying, while those just above the cut-off have almost none. Indeed, the index weights for the stocks in the Russell 2000 just below the 1000 cut-off (e.g. stocks 1001 to 1110) are around ten to fifteen times larger than the index weights for stocks just above the 1000 cut-off (e.g. stocks 990 to 1000). The amounts of money benchmarked to the Russell 1000 and 2000 differ depending on whether one counts passive indexing or total assets benchmarked. But these differences are small relative to the 
index weight shifts across the 1000 cut-off. In fact, even passive Russell 1000 funds optimally do not own the smallest stocks in the Russell 1000 to minimize trading costs. In 2005, the mid-point of our sample, there are a couple of hundred billion dollars of assets benchmarked to the Russell 2000. Therefore we expect a large difference in demand for stocks just below the cut-off and those just above the cut-off.

We show below in a series of validity tests that firm characteristics are continuous around the 1000 cut-off. We then use this random assignment around this cut-off to measure both addition and deletion effects associated with Russell 2000 membership. We examine how our variables of interest behave around this cut-off in the months before and after the end of May. In particular, we anticipate that most of the price effects will play out during June, immediately after the assignment of firms to indices. Importantly, our regression discontinuity design is free of the news critique pointed out by Denis, McConnell, Ovtchinnikov, and $\mathrm{Yu}(2003)$ which affects the S\&P 500 studies.

Although Russell Inc. does not report the end of May capitalizations that they use to place the stocks into indices, it is easy to predict membership using market capitalizations calculated from publicly available data. As such, we can effectively employ a fuzzy RD design (Lee and Lemieux (2010)). Russell follows a strict cut-off at the 1000th firm by market capitalization for all years prior to 2007. After 2007, Russell Inc. followed a more complicated rule to limit switching around the upper cut-off of the Russell 2000. A stock could only change indices if it moved far enough beyond the 1000 cut-off. We can use data on market capitalization to replicate the banding rule and compute the appropriate cut-off in every year. Before banding, around $10 \%$ of the firms in the Russell 1000 switched to the Russell 2000 and around 6\% of the firms in the Russell 2000 switched to the Russell 1000 each year. After banding started, both of these figures dropped to around $3 \%$.

We first measure an addition effect into the Russell 2000 in year $t$ (i.e. at the end of May of year $t$ ) for stocks that were in the Russell 1000 in year $t-1$. Indeed, for the 1996-2012 sample period, we find that stocks from the Russell 1000 that just landed in the Russell 2000, 
based on their market capitalizations at the end of May in year $t$, have discontinuously higher returns in June compared to stocks that just missed making it into the index. Discontinuity plots with data smoothing and break tests all paint the same picture of an economically and statistically significant jump. The optimal bandwidth for these regressions uses stocks ranked within 100 spots of the cut-off. The economic magnitude using local linear regression with the 100 bandwidth is on the order of $5.6 \%$ with a t-statistic of 2.65 . We find that all the price adjustments occur in the month immediately following addition, similar to S\&P 500 studies, and that there are no effects in subsequent months (e.g. July, August,...).

We then measure a deletion effect for stocks in the Russell 2000 in year $t-1$. We compare the returns in June of year $t$ for those stocks that are on either side of the cut-off at the end of May. In contrast to the S\&P 500 studies, we find a deletion effect in which stocks whose market capitalization placed them inside 1000 cut-off (and hence moved into the Russell 1000) have lower returns than stocks just outside the 1000 cut-off (and hence stayed in the Russell 2000). When using the optimal bandwidth of 100 with a local linear regression specification, the economic effect of deletion is $5.4 \%$ with a t-statistic of 3 , which is similar in absolute value and statistical significance to the addition effect. The estimates do move around the $5 \%$ figure when we change bandwidths and regression specifications but there are almost always economically and statistically significant addition and deletion effects. We are able to detect a deletion effect because our randomization yields a better control group than the S\&P 500 methodology of using the market as a control group.$^{1}$

Our methodology also finds that Russell 2000 membership results in more trading in June, consistent with investors rebalancing and tracking. Just added stocks have more trading volume than stocks that just miss addition. And just deleted stocks have more trading volume than stocks that just stayed in the index. This volume finding is consistent with the presence of both addition and deletion effects. Moreover, the level of institutional

\footnotetext{
${ }^{1}$ This difference is also not an artifact of using the Russell 2000 as opposed to the S\&P 500. Indeed, earlier work on the Russell 2000 using the traditional method with the market as a control group, as opposed to our discontinuity approach, finds no deletion effect across the 1000 cut-off (see, e.g., Petajisto (2011)).
} 
ownership does not change significantly with addition or deletion. This suggests that the price increase on addition and decrease on deletion compensate for market-making activities as in Grossman and Miller (1988) and Campbell, Grossman, and Wang (1993), in which institutions with differential preferences for membership stocks trade with each other.

Return correlations with the Russell 2000 are also higher for members of that index, which is consistent with recent theories of the price effects of institutional investor benchmarking (see, e.g., Barberis, Shleifer, and Wurgler (2005), Vayanos and Woolley (2011), and Basak and Pavlova (2012)). Interestingly, the return correlation effects are much larger for deletions than additions. This fact again differs from the literature, which has predominantly only found correlation effects for additions. This suggests that the return correlations of membership stocks with the Russell 2000 take time to build up. However, the price volatility and liquidity of the stocks are not affected by membership. We also briefly examine whether there is a supply response after membership, either through shorting by arbitrageurs or through share issuance by firms.

Finally, we test for addition and deletion effects around the 3000 cut-off. The gain in index weights upon addition at the bottom cut-off is much smaller than at the 1000 cut-off, due to value-weighting. We are only able to estimate the 3000 cut-off effects after 2005 since we do not know the constituents of the expanded Russell 3000E (stocks 1 to 4000) until then. As a result, the estimates of the price effects are much smaller and noisier than at the 1000 cut-off. We are, however, still able to measure similar correlation and trading effects.

In sum, our new methodology delivers fundamentally different results regarding the price effects of stock market indexing. In contrast to the literature, which used the market as a control group, we argue that our regression discontinuity design is free of the earnings news critique of Denis, McConnell, Ovtchinnikov, and Yu (2003) which affects S\&P 500 studies and as a result we are able to identify a robust deletion effect. This is not to say that there are no indexing effects for the S\&P 500 index but that cleanly identifying indexing effects from other potential confounds is difficult in the S\&P 500 setting. 
Our paper proceeds as follows. We discuss the background on how the Russell 2000 index membership is determined and the premise behind the regression discontinuity approach in Section 2. Data and variables are described in Section 3. The results are presented in Section 4. We conclude in Section 5.

\section{Constructing Russell Rankings and Regression Dis- continuity Design}

The key to our empirical design is to verify the smoothness in total market capitalization across the two cut-offs on the last trading day of May. Exact rankings are not available because Russell only publishes the reconstituted index lists and end-of-June weights, not the total market capitalization rank at the end of May. Fortunately, it is possible to calculate each stock's market capitalization. The transparency of this process, in contrast to the black box approach of the S\&P 500 index, is also what makes the Russell indices attractive to many money managers for the purposes of indexing and benchmarking.

In this section, we explain in detail how Russell constructs their indices and the validity of our regression discontinuity approach. Every year on the last trading day in May, eligible stocks are ranked by their market capitalizations. Stocks ranked 1-1000, 1001-3000, and 1-4000 constitute the member stocks for the Russell 1000, Russell 2000, and Russell 3000E, respectively. We focus on the 1000 and 3000 cut-offs that represent the upper and lower end of Russell 2000. Subsequently, index reconstitution takes place on the last Friday of June, when the weights of member stocks are determined by their float-adjusted market value rank within each index. The float adjustment to outstanding shares accounts for cross-ownership by other index firms, private holdings, government holdings, etc. We obtain annual constituent lists for the Russell 1000 and Russell 2000 from Russell Inc. starting in 1996. The broadest Russell index, the Russell 3000E, is available from 2005 onwards.

Note that starting with its 2007 reconstitution, Russell initiated a banding policy around 
the 1000 cut-off to mitigate index turnover. If an index member's market capitalization does not deviate far enough to warrant an index membership change, it will remain in its original index. The exact methodology computes the cumulative market capitalization of every stock, from the smallest to the largest, as a percentage of the total market capitalization of the Russell 3000E. Stocks only switch from their current index if they move beyond a 5\% range around the market capitalization percentile of the 1000th stock. By this logic, a stock that is ranked 900 in year $t-1$ and whose market capitalization on the last trading day of May in year $t$ is ranked 1050 stays in the Russell 1000 if its cumulative market capitalization percentile is not more than $2.5 \%$ below that of the 1000 th stock. We use data on market capitalization to compute these percentiles and the implied cut-offs for every year in which banding is used. There is no banding for the 3000 cut-off.

\subsection{Constructing Our End-of-May Market Capitalizations and Rankings}

To recreate the rankings that determine index membership, we take all 3,000 firms in the Russell 3000 universe and use the publicly available prices and shares at the end of the last trading day in May. End-of-May share prices are obtained from CRSP. To measure the number of shares at the company level, we use Compustat quarterly shares outstanding (CSHOQ). Since CSHOQ are updated only quarterly, we use Compustat quarterly earnings report date (RDQ) to determine which quarter's CSHOQ is publicly available on the last trading day of May. For those firms with missing RDQ, the following rules are used: (1) Before 2003, the SEC required firms to file 10-Ks within 90 days of their fiscal year-end. The policy was changed to 75 days from 2003 to 2006 for firms with market capitalization larger than 75 million dollars. Starting in 2007, this was further shortened to 60 days for firms with market capitalization of at least 700 million dollars. (2) For 10-Q filings, the SEC filing deadline is 40 days after the quarter ends before 2003. It is 40 days for firms larger than 75 million dollars starting in 2003. Following these rules, we obtain the most recent 
fiscal quarter-end before May 31st and assume the number of shares is publicly available after these deadlines. Next, we use monthly CRSP factor to adjust shares (FACSHR) for any corporate distribution after the fiscal quarter-end and before May 31st. For any missing prices and shares, we hand-collect the data from Bloomberg. Finally, we choose the larger of the shares obtained from this procedure and the CRSP shares.

For the Russell 2000 lower cut-off tests, we repeat the same exercise using all Russell3000E firms. Note that the Russell 3000E data is available starting from 2005 onwards so our analysis for the lower cut-off is limited to the 2005-2012 sample.

\subsection{Smoothness of Our End-of-May Market Capitalizations with Rankings}

The validity of our experiment relies on the random assignment of stocks around the upper and lower cut-offs on the last trading day of May. This is true if firms have imprecise control over which side of the cut-offs they end up on. To the extent that we have local randomization, we can then perform a quasi-natural experiment using a regression discontinuity approach around these two cut-offs. This allows us to make causative inferences on the effect of indexing. We do the formal validity tests below, but it is instructive to see that market capitalizations on the last day of May are continuous across the upper and lower cut-offs.

Figure 1 plots the market capitalizations of firms on either side of the upper Russell 2000 cut-off against the ranks determined by these market capitalizations, both before and after banding was implemented. Figure 2 plots the market capitalizations around the bottom 3000 cut-off. Notice that market capitalizations are smoothly declining across the cut-offs when banding is not in effect, supporting the assumption of random assignment. Firms on the LHS (RHS) of the vertical line are larger (smaller) and will be in Russell 1000 (Russell 2000) following the end-of-June reconstitution. After banding, market capitalization is not as clearly declining because smaller firms can remain in the Russell 1000 while larger firms remain in the Russell 2000. However, there is still no discontinuity at the cut-off. 


\subsection{Discontinuities in Index Weights, Upper Cut-off}

To demonstrate the essence of our regression discontinuity design, in Figures 3 and 4 we plot the index weights for stocks around the upper cut-off of the Russell 2000 in the period before banding. During that time period, an average of $10 \%$ of the firms in the Russell 1000 switched to the Russell 2000 every year. Of the stocks starting in the Russell 2000, 6\% switched to the Russell 1000 and 13\% fell out of the Russell 3000 altogether.

For the stocks in the Russell 1000 in year $t-1$, we plot in Figure 3(a) these stocks' index weights on the last day of May against the stocks' ranks. Notice that the index weights are smoothly declining with their end-of-May ranks as one would expect in a value-weighted index. The weights are updated daily to account for changes in a firm's number of shares. The weights range from around $0.04 \%$ for the stocks around the 600 rank to a low of $0.005 \%$ for stocks at the 1400 rank. The stocks around the 1000 rank have weights around $0.01 \%$. Notice that the number of observations declines with rank. The reason is that since we are looking at only the Russell 1000 constituents, most will tend to lie above the 1000 cut-off.

In Figure 3(b), we plot for these same stocks their end of June index weights. Now there is a jump in the weights at the 1000 cut-off since stocks below the 1000 cut-off will belong to the Russell 2000 in June and have a higher weight in the Russell 2000 index while the stocks above the cut-off remain in the Russell 1000. For the stocks just to the right of the 1000 cut-off, the weight is now at least $0.05 \%$ and the average of the changes in weight is on the order of $0.1 \%$ to $0.15 \%$. This is a ten-fold to fifteen-fold increase in index weights from a base of $0.01 \%$. For the stocks above the cut-off, there is no change in weights and they remain at around $0.01 \%$.

In Figure 3(c), we plot the corresponding change in weights for these stocks by their rank on the last day of May to make this point more clearly. One take-away from this analysis is that even assuming that the amount of money tracking Russell 1000 is twice as much as the Russell 2000 (which is one set of estimates we show below), we would still expect a significant jump in demand for stocks below the 1000 cut-off relative to stocks above the 
cut-off. Figure 3 makes it clear that we should expect an addition effect when we consider stocks starting in the Russell 1000 and compare the returns of those that just made it into the Russell 1000 to those that just missed it.

Something to note throughout this analysis is that the index weight changes are likely to under-estimate the true demand shift because most index funds or funds benchmarked to an index are not likely to hold the smallest stocks in the index in order to track it. This is an outcome of optimal trading with frictions since the smallest stocks matter so little that most of the tracking error reduction can be achieved simply by owning the members with the highest weights. For instance, BlackRock, the world's largest indexer, has a Russell 1000 ETF and their holdings skip at least the last 30 stocks.

Figure 4 repeats the same exercise as Figure 3 but for stocks that were in the Russell 2000 in the previous year. In Figure 4(a), we plot the end-of-May weights for the Russell 2000 members against their ranks. Since we are looking at members of the Russell 2000, most of the observations lie below the 1000 cut-off but there are some whose ranks have risen above 1000. Notice that the weights for the stocks at the 1000 cut-off are around $0.1 \%$ to 0.15\%. In Figure 4(b), we see that those to the left of the cut-off experience a drop in their June weights since they become part of the Russell 1000 and have very little weight in that index.

Figure 4(c) shows that the change in the index weights is indeed negative for those stocks above the 1000 cut-off. In fact, the drop in the weights for those to the left of the 1000 cut-off (i.e. the deletions from the Russell 2000) is around $-0.1 \%$ to $-0.15 \%$, similar to the jump upwards for additions into the Russell 2000 from the Russell 1000. Therefore, we expect to find addition and deletion effects of equal sizes. The logic of these calculations also highlights why it is puzzling that the indexing literature up until now has not found any evidence of a deletion effect.

In Figures 5 and 6, we show the index weights for firms crossing the upper cut-off for the Russell 2000 after the banding policy was implemented in 2007. Notice that the discon- 
tinuities are no longer at 1000 but that the cut-off for Russell 1000 firms moving into the Russell 2000, shown in Figure 5, is lower. Similarly, the cut-off for Russell 2000 firms moving into the Russell 1000 is higher, as shown in Figure 6. There are fewer firms switching every year, as one would expect with an effective banding policy. On average, $3 \%$ of the stocks in the Russell 1000 switch to the Russell 2000. Of the stocks starting in the Russell 2000, $2 \%$ switch to the Russell 1000 and $8 \%$ drop out by crossing the lower cutoff. However, the magnitudes of the changes in weights are similar to those before banding. As such, we still expect to find significant price effects from indexing after incorporating the post-banding sample.

\subsection{Discontinuities in Index Weights, Lower Cut-off}

In Figures 7 and 8, we show the weight changes that occur for additions and deletions across the bottom 3000 cut-off. We find a modest change in index weights across the 3000 cut-off, in contrast to the sizable changes across the 1000 cut-off. But again, this weight change is probably an over-estimate because the smallest stocks in the Russell 2000 have so little weight in the index that they may be skipped over by indexers. On the other hand, these stocks are smaller so modest indexing changes may still translate into meaningful price effects.

\subsection{Money benchmarked to Russell 1000 and 2000 and a Priori Significant Price Effects}

We can take these weight changes and multiply by the amount of money following the Russell 1000 and 2000 to get an estimate of how big of a price effect we might expect. The typical difference in weight change around the upper cut-off is, from our analysis above, around $0.1 \%$ to $0.15 \%$

In Panel A of Table 1, we report the amount of passive capital benchmarked to Russell 1000 and Russell 2000. This data is from a Russell internal report that surveys its passive 
clients every year at the end of June. However, these numbers are provided "as-is" and Russell does not independently audit the numbers. We obtain this data from a contact at the research division at Russell. ${ }^{2}$ Panel B of Table 1 shows the total assets benchmarked for S\&P 500, Russell 1000, and Russell 2000. We show both the number of products and dollar amount benchmarked to these indexes. The data is obtained from Russell Investment's 2008 US Equity Indexes: Institutional Benchmark Survey. ${ }^{3}$ The numbers here include both passive and active benchmarking and are assessed by Russell every year from 2002 to 2008 at the end of May.

From the unaudited surveys in Panel A of Table 1, the amount of passive assets is around 2 to 3.5 times bigger for the Russell 1000 index. For instance, in 2005, the amount is around 2.5 times as big, with 93.3 billion tracking Russell 1000 and 39.2 tracking Russell 2000. Notice that since the index weight change is on the order of 10 to 15 times from rank 1000 to rank 1001, this two-fold difference in amounts indexed is small compared to the weight shift. In Panel B, we report the total amount of money benchmarked to these two indices using Russell's cleaned estimates. When benchmarking is considered, the Russell 2000, at around 200 billion dollars in 2005, is more popular than the Russell 1000, which is tracked by only 90 billion dollars. Our contact at Russell pointed out that the estimates from the unaudited surveys for passive benchmarking are typically larger than the official numbers that Russell Inc. publishes. Notice also that there are many more products following Russell 2000 than Russell 1000. Of course, the interest in these two indices is dwarfed by that in the S\&P 500 .

Since there is probably more forced buying from passive indexing than active benchmarking, we conclude that both indices have substantial amounts of money tied to them and that these amounts are roughly in the same ball park. To gauge the expected effect of tracking, we use an estimate of 100 billion dollars, which is roughly mid-way between the high estimate of total assets benchmarked to the Russell 2000 (at around 200 billion dollars) and the low estimate of passive assets tracking the Russell 2000 (at around 39 billion dollars). With one

\footnotetext{
${ }^{2}$ We thank Mark Paris of Russell for his help.

${ }^{3}$ This report is online at http://www.russell.com/JP/PDF/Index/2008_US_BenchmarkSurvey_E.pdf.
} 
hundred billion dollars tracking the 2000 index, we expect 100 million dollars of index buying for stocks at the cut-off. The stocks around this cut-off have an average market capitalization of 1.4 billion. This translates into a $7 \%$ increase if there was a one for one effect on price. Of course, demand is not completely inelastic, so this calculation serves as an upper bound on the price effect we might reasonably expect to observe with 100 billion dollars tracking the index. This is a sizeable figure so we would expect to detect some economically interesting price effects.

\subsection{Non-Valid RD using Russell Index End of June Weights}

Since end of May market capitalization does not perfectly predict addition, although it comes close, one may be tempted to use index membership after reconstitution to back out May rankings. In the Internet Appendix to our paper, we show that it is not desirable to perform the RD design using end-of-June Russell index weights ${ }^{4}$. After index membership has been determined in May, reconstitution is complete when the weights of index members are determined using firms' float-adjusted market capitalization on the last Friday of June. Therefore one could try to use the end-of-June Russell index weights to rank stocks 1-1000 in the Russell 1000 and stocks 1001-3000 in the Russell 2000. However the comparison between the just added and just deleted stocks is biased using this ranking method.

This methodology has two biases that make it much less clean than our current approach. First, for firms with market capitalization above the 1000 cut-off, those with less tradable shares are more likely to end up with a lower Russell Index weight on the last Friday of June. Russell Inc. is not entirely transparent about how these float adjustments are made, which makes it difficult to map the final weights to the rankings used to determine addition. We show in the Internet Appendix that this bias is significant because all the most illiquid stocks are placed at the bottom of the Russell 1000. Indeed, the end-of-May market capitalizations of these stocks are much higher than those ranked just below 1000. In other words, ranking

\footnotetext{
${ }^{4}$ The internet appendix is available online at http://www.princeton.edu/ ${ }^{\sim} h h o n g / r d 2000 a p p e n d i x$.
} 
using the end of June weights violates the assumption of random assignment across the cut-off.

The second bias is due to the fact that the new index weights after each year's reconstitution already encompass stock performance in June. This means that sorting on index weights is an approximate sorting on June performance itself, which again violates the assumption of random assignment and renders the RD invalid. For these two reasons, an RD analysis using this ranking will yield biased estimates. Indeed, the RD estimate for June returns using this method is a misleading 20\%. Other variables of interest such as institutional ownership also yield sizeable and misleading discontinuities.

\section{Data}

All other variables are from CRSP and Compustat. The independent variable of interest is the end-of-May rankings of stocks' market capitalizations (MKTCAP). Our main dependent variables of interest include the following: RET is the raw monthly stock return. CORR2000 is the correlation coefficient between daily stock returns and Russell 2000 index returns in a given month. VOL is the standard deviation in daily stock returns in a given month. ILLIQ is the Amihud (2002) illiquidity measure, in percentage per million-dollar volume. Volume ratio for stock $i$ in month $t$ is defined as $V R_{i, t}=\left(V_{i, t} / V_{i}\right) /\left(V_{m, t} / V_{m}\right)$, where $V_{i, t}$ and $V_{m, t}$ are the trading volumes of stock $i$ and of the market. $V_{i}$ and $V_{m}$ are the average trading volume of stock $i$ and the market over the past 6 months, not including month $t$. Trading volume on the NASDAQ is adjusted using the Gao and Ritter (2010) procedure. SR is the monthly short interest ratio, the ratio of shares shorted to shares outstanding for each stock. ISSUANCE is the ratio of shares issued to initial shares, computed as in Campello and Graham (2013). Other fundamental variables that serve as additional validity checks include the following: ROE and ROA are the return-to-equity and return-to-asset. EPS is the earnings-per-share excluding extraordinary items. FLOAT is the number of floating shares 
(in thousands) provided by Russell. ASSET is the asset value (in millions). CASH/ASSET is the cash-to-asset ratio and ICR is the interest coverage ratio.

Table 2 reports summary statistics for the Russell 1000 and 2000 firms. The mean and standard deviation of RET is somewhat higher for Russell 2000 stocks than for Russell 1000. The median market capitalization (MKTCAP) is 4.22 billion dollars for Russell 1000 stocks and around 0.5 billion for Russell 2000 stocks. The correlation of the Russell 1000 stocks with the Russell 2000 index (CORR2000) is similar to the correlation of the Russell 2000 stocks with the Russell 2000 index. VOL and ILLIQ are higher for Russell 2000 stocks than their Russell 1000 counterparts, while IO is lower. These patterns are to be expected given that we already know that small stocks have higher volatility, less liquidity and have lower institutional ownership than large stocks. ISSUANCE is on average higher for the top 1000 stocks. There is also less shorting of the top 1000 stocks. The Russell 2000 firms are less

likely to repurchase shares. They have lower ROA, ROE, EPS and ASSET. The cash to assets ratio $(\mathrm{C} / \mathrm{A})$ is comparable across the two groups and so is interest coverage ICR. Russell 2000 stocks, not surprisingly, have lower FLOAT than the top 1000 stocks.

\section{Results}

\subsection{Fuzzy RD Regression Specifications}

To formally test the significance of addition to the Russell 2000 index, we use a fuzzy regression discontinuity design. Because our measure of market capitalization is not exactly the same as that used by Russell Inc., our rankings cannot perfectly predict membership in the index. The only factor that affects index membership, other than our rankings, is the difference between our measure of market capitalization and that used by the Russell Index. Therefore treatment is determined partly by whether the ranking crosses the cut-off and partly by measurement error. As a case of local random assignment, this is an appropriate setting for fuzzy RD design. We use two-stage least-squares, as suggested by Hahn, Todd, 
and der Klaauw (2001), to estimate the effect of index membership.

The instrument in this framework is an indicator variable $\tau$ for whether a firm of rank $r$ is on the side of the cut-off $c$ required for index membership. In the case of the upper cut-off, $c$ is 1000 before banding and is calculated separately every year after banding is implemented. For the lower cut-off, $c$ is 3000 . The indicator variable $D$ identifies subsequent membership in the Russell 2000 from data on actual index constituents in every year. The first stage regression estimates

$$
D_{i t}=\alpha_{0 l}+\alpha_{1 l}\left(r_{i t}-c\right)+\tau_{i t}\left[\alpha_{0 r}+\alpha_{1 r}\left(r_{i t}-c\right)\right]+\varepsilon_{i t}
$$

for each firm $i$ and year $t$. The resulting estimates of $\alpha_{0 r}$ are reported below. If our instrument $\tau$ is a perfect predictor of membership, the coefficient $\alpha_{0 r}$ would be one. We estimate this first stage separately for addition and deletion.

For the second stage, we estimate a similar relationship between ranking and the outcome variable. For outcome of interest $Y$, we estimate the equation

$$
Y_{i t}=\beta_{0 l}+\beta_{1 l}\left(r_{i t}-c\right)+D_{i t}\left[\beta_{0 r}+\beta_{1 r}\left(r_{i t}-c\right)\right]+\epsilon_{i t}
$$

The resulting estimates of $\beta_{0 r}$ are reported as the effect of addition or the negative of the effect of deletion.

We use a local linear regression to non-parametrically estimate the effects of addition and deletion close to the cut-off. The choice of bandwidth defines how many firms on either side of the cut-off are considered close. This choice balances the benefits of more precise estimates as the sample size grows and the costs of increased bias. Using the rule-of-thumb (ROT) bandwidth presented in Lee and Lemieux (2010), we calculate the optimal bandwidth. It varies with the range of firms deemed relevant, but in general it is close to 100. Our preferred specification uses a bandwidth of 100 and linear functions of ranking on either side of the cut-off. However, results are robust to changes in the bandwidth and to quadratic functions 
of ranking. When using the quadratic specification, we estimate the first stage regression

$$
D_{i t}=\alpha_{0 l}+\alpha_{1 l}\left(r_{i t}-c\right)+\alpha_{2 l}\left(r_{i t}-c\right)^{2}+\tau_{i t}\left[\alpha_{0 r}+\alpha_{1 r}\left(r_{i t}-c\right)+\alpha_{2 r}\left(r_{i t}-c\right)^{2}\right]+\varepsilon_{i t}
$$

and the second stage regression

$$
Y_{i t}=\beta_{0 l}+\beta_{1 l}\left(r_{i t}-c\right)+\beta_{2 l}\left(r_{i t}-c\right)^{2}+D_{i t}\left[\beta_{0 r}+\beta_{1 r}\left(r_{i t}-c\right)+\beta_{2 r}\left(r_{i t}-c\right)^{2}\right]+\epsilon_{i t}
$$

It is important to note that it is not necessary to control for other variables or fixed effects if the RD is valid. Lee and Lemieux (2010) argue that the use of other baseline covariates in an RD design is primarily to reduce sampling variability. Firms falling above or below the 1000 cut-off are randomized and there should not be significant differences in firm characteristics prior to the rankings.

\subsection{First Stage Regressions}

In Table 3, we show the first stage regressions of the fuzzy RD design. In Panel A, we present the first stage regressions for the addition effect at the 1000 cut-off, the upper cut-off after the implementation of the banding policy, and the 3000 cut-off. The sample of stocks for these regressions is those that are not in the Russell 2000 in year $t-1$ and that are within 100 spots of the cut-off based on their end-of-May market capitalization in year $t$. For the upper cut-off, the coefficient of interest is 0.785 with a t-statistic of 31.5 . The adjusted $R^{2}$ of this regression is 0.86 . After banding, the coefficient is 0.82 with a t-statistic of 13 and an $R^{2}$ of 0.845 . The coefficient on the lower cut-off at 3000 is 0.862 with a t-statistic of 48.86 and an $R^{2}$ of 0.93 .

In Panel B, we present the first stage regressions for the deletion effect at the 1000 cut-off, the upper cut-off after banding, and the 3000 cut-off. The sample of stocks is the Russell 2000 stocks in year $t-1$ and that are within 100 spots of the cut-off based on their end-ofMay market capitalizations in year $t$. For the upper cut-off, the coefficient is 0.705 with a 
t-statistic of 29. The adjusted $R^{2}$ of this regression is 0.81 . After banding, the coefficient is 0.759 with a t-statistic of 20.90 and an $R^{2}$ of 0.878 . The coefficient on the lower cut-off at 3000 is 0.86 with a t-statistic of 39.79 and an $R^{2}$ of 0.91 .

The first stage regression is extremely strong in all cases. We cannot perfectly predict membership but on average, a firm is 70 to $80 \%$ more likely to be added to the Russell 2000 when the cut-off is crossed. The first stage regressions are similar before and after banding, which indicates our estimates of the post-banding cut-offs are accurate.

\subsection{Russell 1000 Cut-off}

We begin our empirical analysis with the Russell 1000 cut-off during the period 1996-2012. This set of results considers the upper cut-off for Russell 2000 index membership. We divide our analysis into first measuring an addition effect using stocks starting in the Russell 1000 and then a deletion effect using stocks starting in the Russell 2000.

\subsubsection{Returns}

In Table 4, we report the fuzzy RD results for the effect of addition on raw returns. The outcome variable is monthly stock returns and the independent variable is an indicator for addition to the Russell 2000 index. Monthly returns are shown for the month immediately before (May) and four months following index membership determination (June, July, August and September). T-statistics are reported in parentheses. The bandwidth specifies the range of firms on either side of the cut-off that was included in the estimation. For each bandwidth, the RD estimate is shown using both a linear $(p=1)$ and quadratic $(p=2)$ polynomial in firm ranking that is allowed to vary on either side of the cut-off. Only firms that were members of the Russell 1000 index at the end of May are used.

We report the results for different bandwidths and different regression specifications. Our

preferred specification uses the optimal bandwidth of 100 . With an optimal bandwidth of 100, a local linear regression $(p=1)$ is the preferred specification. Notice that for $p=1$, the 
coefficient of interest for June returns is .05 and is significant at the $1 \%$ level. This means there is a $5 \%$ addition effect when comparing firms that just crossed the 1000 cut-off and firms that just missed it. This $5 \%$ figure is our baseline estimate. For $p=2$, the coefficient is 0.11 and significant at the $1 \%$ level.

Notice that there are no statistically significant coefficients in any other months. In particular, we should not see any noticeable return effects in May if our design is valid, given that membership is determined at the end of that month. In contrast, we might expect positive return effects for not only June but also for subsequent months if institutional investors gradually begin to track the Russell 2000 after May. Alternatively, we might expect there to be a positive effect for June followed by negative returns in subsequent months if there are reversals. The fact that we only see a return effect for June and none in following months means that there are no significant reversals.

There is a trade-off between having more observations, which a wider bandwidth affords, and cleanly identifying a discontinuity, which is easier with a narrow bandwidth. While we have focused our discussions on the 100 bandwidth and the local linear regression, it is still useful to consider other bandwidths and specifications to get a feel for how our estimate of the addition effect moves around as we vary these parameters.

For the regression specification with bandwidth of 50 and $p=1$, the coefficient for June is 0.11 and it is significant at the $1 \%$ level. However, when one looks at $p=2$, the coefficient is only 0.061 and is statistically insignificant. The 50 bandwidth does not yield many observations around the cut-off and so the estimates would be expected to bounce around. None of the other months are significant, which highlights the evidence for an addition effect in June.

With a bandwidth of 200 , the coefficient of interest for $p=1$ is 0.022 with a t-statistic of 1.84. For $p=2$, it is .060 and significant at the $1 \%$ level. Finally, with a bandwidth of 300 , there is still evidence of an addition effect. For instance, for $p=2$, the coefficient is 0.036 with a t-statistic of 2.23. Interestingly, we also detect a statistical significant addition effect 
in August of 3.9\%. Notice that the estimates move around the $5 \%$ figure as we change specifications but in all cases we are detecting economically and statistically significant effects.

In Figure 9, June returns are plotted against market capitalization rankings. All firms shown were in the Russell 1000 index in May. The firms that stay in the Russell 1000 are on the left hand side of the cut-off. The firms that move into the Russell 2000 are on the right hand side. These are the firms that identify the addition effect. The lines drawn are linear functions of rank on either side of the cut-off. Results are shown using bin widths of 2, 5 and 10. We expect the just added stocks to have a positive demand shift, and thus a higher June return. Indeed, there is a visible jump in RET in June. ${ }^{5}$

In Table 5 we report the fuzzy $\mathrm{RD}$ results for the deletion effect on raw returns. The outcome variable is monthly stock returns and the dependent variable is an indicator for staying in the Russell 2000 index. Only firms that were members of the Russell 2000 index at the end of May are used. Again we report results for different bandwidths and different polynomial specifications on either side of the cut-off. Note that there are more firms starting in the Russell 2000 than in the Russell 1000. Therefore the sample sizes are larger and the estimates are more precisely estimated for the deletion effect.

When the optimal bandwidth of 100 is used, notice that for $p=1$, the coefficient of interest for June returns is 0.054 and significant at the $1 \%$ level. This means that there is a nearly $5 \%$ deletion effect when comparing firms that crossed the 1000 cut-off to firms that did not. This point estimate is very similar to the estimate for addition when the bandwidth is 100 and $p=1$. For $p=2$, the coefficient is now 0.052 with a t-statistic of 1.48. The coefficient should be positive and not negative for deletion since we are comparing the returns of those who just stayed to those who just got deleted, which we expect to be positive since deletion leads to lower returns.

With a bandwidth of 50 and a linear specification, the coefficient for June is .052 with a

\footnotetext{
${ }^{5}$ Note that we are presenting raw returns. Stocks on either side of the 1000 cut-off in this addition exercise were Russell 1000 stocks in the prior year whose values fell. These stocks had negative June returns over our sample period. But just-added stocks received a positive price shock due to indexing, thereby bringing their raw returns closer to zero.
} 
t-statistic of 1.64. Using a quadratic specification, the coefficient is statistically insignificant. For a bandwidth of 200, the coefficient of interest for $p=1$ is 0.044 with a significance level far exceeding $1 \%$. For $p=2$, it is 0.053 with a significance level of $1 \%$. Finally, using a bandwidth of 300, the deletion effect is still economically and statistically significant. For $p=1$, the deletion effect is 0.029 and significant at the $1 \%$ level. For $p=2$, the deletion effect is 0.053 and significant at the $1 \%$ level. There are no return effects in May, which confirms the validity of the RD, and there are no subsequent return effects beyond June.

In Figure 10, we plot these results for June returns. All firms shown were in the Russell 2000 index in May. The firms that moved into the Russell 1000 are on the left hand side of the cut-off. These are the firms that identify the deletion effect. The firms that stayed in the Russell 2000 are on the right hand side. There is a visible discontinuity in returns for stocks that stayed in versus stocks that dropped out of the Russell 2000 index. $^{6}$

Overall, the key take-away from these results is that there is both a strong addition and deletion effect. This stands in contrast to the results found using the old methodology, which confounds the addition effect with earnings changes and consistently fails to find a deletion effect. Notice that while the June estimates do bounce around our favored baseline figure of $5 \%$, they are generally positive and in the ballpark of the effects implied by the earlier back of the envelope calculations. We have not reported more months surrounding June for brevity, but they all show statistically insignificant effects. One interpretation of the addition and deletion effects is that our method picks up a forced tracking effect whereas the old methodology is mixing both a tracking effect and a recognition effect.

\subsubsection{Comovement and Price Volatility}

We continue our empirical analysis by looking at the fuzzy RD results for co-movement (CORR2000) and price volatility (VOL) in Table 6. We first report fuzzy RD tests for the

\footnotetext{
${ }^{6}$ Note that we are presenting raw returns. Stocks on either side of the 1000 cut-off in this deletion exercise were in the Russell 2000 the prior year and had run-ups in value. This group of stocks had positive June raw returns over our sample period. But just-deleted stocks receive a negative price shock due to a drop off in indexing, thereby bringing their raw returns closer to zero.
} 
addition effect. There are no pre-addition effects for CORR, as we would expect. There is also an insignificant effect for the months of June and July. However, correlation with the Russell 2000 is significantly higher in August and September for just added stocks relative to stocks that just missed addition. The coefficients for August and September are 0.122 and 0.092 with t-statistics of 2.79 and 2.04 , respectively. These patterns suggest that addition leads to a gradual increase in the correlation of the added stocks with the Russell 2000 index.

We also report the deletion effects for CORR in Table 6. We see that the stocks that just stayed in the index subsequently have much higher correlations than stocks that just get dropped. Again, there are no pre-deletion effects, as we would expect in the case of random assignment. In the month of June, stocks that just stayed have a 0.132 higher correlation than stocks that just got dropped from the Russell 2000 index. The t-statistic is a highly significant 3.47. This higher correlation is persistent, with significant positive coefficients in July and September. The correlation effects of deletion are larger than those of addition. This result, and the gradual rise of correlation after addition, imply that it takes time for correlation between member stocks and the Russell 2000 index to develop. The stocks that get dropped from the index have had more time in the index to develop this correlation so we see a dramatic decline once they are deleted. Our covariance finding differs from those in the literature. For instance, Greenwood (2008), who looks at the one-time event of the Nikkei 225 re-weighting in the Japanese stock market, and Boyer (2011), who considers the mis-labeling by S\&P/BARRA classifications of stocks into different categories, identify excess co-movement effects associated with indexing but do not speak to how long it takes for this higher correlation to develop.

We next consider VOL, also reported in Table 6. Indexing, either through addition or non-deletion, does not lead to higher price volatility. There is some evidence that stocks in the Russell 2000 index experience higher volatility, as implied by the 0.005 coefficient for the month of September under the deletion effect panel. However, the coefficient is economically small. Otherwise, the RD estimates for all months are statistically insignificant and close 
to zero. We conclude that addition leads to higher correlation but has no price volatility effects.

\subsubsection{Trading, Ownership and Liquidity}

We next discuss the findings for trading volume ratio (VR), institutional ownership (IO), and illiquidity (ILLIQ) shown in Table 6. Notice that addition leads to a dramatic increase in VR in the month of June. The estimate in June is 0.478 with a t-statistic of 3.14. This effect is around $50 \%$ of a one standard deviation change in VR among Russell 2000 firms. As expected, there are no effects in the months preceding the reconstitution. The elevated trading after addition reflects a shift of indexing or benchmarking money into the added stocks. We also find that stocks that get deleted experience elevated trading volume in the month of June relative to stocks that stay in the index. This higher turnover makes sense as it reflects that index money is leaving the dropped stocks due to decreased demand. The coefficient is -0.263 , with a t-statistic of 2.74 . This is a substantial change in trading relative to the standard deviation of VR.

The observed rise or fall in demand due to indexing or benchmarking can be met by other institutional investors, ones that do not have inelastic demand for indexed stocks and can therefore sell on additions and buy on deletions, or it can be met by retail investors. To see who meets the changes in demand, we compare how institutional ownership levels change with addition and deletion. There appears to be a small and statistically insignificant rise (fall) in institutional ownership with addition (deletion). For instance, the coefficient for addition in June is .031 with an insignificant t-statistic of 0.77 . Recall that IO is only available quarterly. For deletion, we see a coefficient of -0.063 for June but again it is statistically insignificant. The coefficient for September is -0.037 , already half the size of the June effect, and is also statistically insignificant. The average level of institutional ownership in the sample around 0.65 to 0.7 , so the point estimates are not small but they are not statistically significant. Overall it seems that the trading of indexed stocks does not 
result in changes in the level of institutional ownership. Those with less inelastic demand for index member stocks provide market making activities to those with more inelastic demands for these stocks. We also do not detect any indexing effects for ILLIQ.

\subsubsection{Supply Response by Firms or Short-Sellers}

One interesting analysis that has been absent from the literature is the extent to which either the firm or short-sellers might provide shares of index member stocks to meet the excess demand evidenced by the price effect. First, note that the price effect, on the order of $5 \%$, is not large. So any type of firm issuance is not a priori likely given that stock issuance has large signaling implications and typically leads to a steep discount in the price of the shares issued. Consistent with this perspective, we find little response in the ISSUANCE variable shown in Table 6. If anything, it appears that the addition effect leads to less issuance in the year after addition. The result is only available for June because this is an annual variable whose exact timing depends on the firm's fiscal year but always includes the month of June. Overall, firms that get added into the index do not issue more than firms that are not. We can also investigate the supply response of investors by looking at the short interest ratio (SR). We do not see any increase in SR for stocks that get added or remain in the index so the supply responses from both firms and short-sellers appear to be very muted.

\subsubsection{Validity Tests and Incentives to Manipulation of Reconstitution Ranks by Hedge Funds}

We now formally show that attributes determined before the end-of-May ranking are smooth across the cut-off. For example, if companies with resources can manipulate their stock prices and thus qualify for a more popular Russell index, this will distort the random assignment around the index cut-offs and potentially render the RD framework invalid. In this section, we perform validity checks on a host of fundamental variables. Following Lee and Lemieux (2010), we test our RD design by ensuring that all variables determined prior to the realiza- 
tion of the treatment are smooth. This is crucial to the assumption of local randomization.

Table 7 reports the results of a fuzzy RD design for market capitalization (MKTCAP) for the addition effect. The outcome variable is market capitalization, measured in billions of dollars, at the end of May. The independent variable is an indicator for addition to the Russell 2000 index. All regressions use firms with end-of-May ranking within 100 spots of the predicted cut-off. The regression specification includes a linear function of ranking that is allowed to vary on either side of the cut-off. Only firms that were members of the Russell 1000 index at the end of May are used. It is easy to see that there are no breaks in market capitalization.

We illustrate a number of other firm fundamentals around the index cut-off prior to the May ranking. These include profitability (ROE, ROA, and EPS), number of floating shares (FLOAT), and size (ASSET). One can see that before the end-of-May ranking, there are no significant discontinuities in any of the variables we consider.

One argument that could invalidate the RD design is manipulation by the less financially constrained firms. It is conceivable that firms close to the cut-off with more financial slack can decrease their market capitalization by repurchasing shares. Firms that are more financially constrained are not able to do this and are thus stuck in the bottom of Russell 1000. To alleviate this concern, we look at the repurchasing activities (REP) of the firms around the index cut-off. We do not find discontinuities for any of these variables. There are also not any discontinuities in ICR or C/A, which are also related to a firm's financial status.

In the bottom half of Table 7, we report analogous estimates for the deletion effect. Again there are no significant breaks across the 1000 cut-off. In this table all the outcome variables are measured in the fiscal year prior to the end of May ranking. We have also examined the same set of variables in the fiscal year of the reconstitution and did not find any discontinuities.

The smoothness of firm fundamentals around the cutoff are displayed graphically in Figure 11 for some variables. Subfigures (a) and (b) show that there are no differences 
in returns between added and deleted firms in the month of May, leading up to the June reconstitution. Likewise, there are no discontinuities around the addition or deletion cut-offs for assets or earnings per share. For addition, there appears to be slight break in assets but it is not pronounced and does not appear to be significant in the regressions reported above. Therefore the RD is not capturing differences in firm fundamentals that could be correlated with future returns.

There is also little incentive for hedge funds to manipulate the indexing effects at the 1000 cut-off. The reasoning is as follows. To push a stock from the Russell 1000 into the Russell 2000 would require hedge funds to short the stock. But addition to the Russell 2000 means higher prices which would lead to negative profits to shorting. Similarly, pushing a stock in the Russell 2000 out of the index and across the 1000 cut-off requires hedge funds to buy the stock and drive its price up. But deletion results in lower prices which would negate the point of buying ahead of the index reconstitution. There is of course potential manipulation concerns at the 3000 cut-off, which we address below. But such concerns are unlikely at the 1000 cut-off.

Moreover, it is typical in studies with RD designs to conduct the McCrary (2008) test to assure there is no "bunching" in the assignment variable. If there is manipulation, one will see a higher number of observations just passing the cutoff and fewer observations just missing it. But in our design there is exactly one firm for each ranking position and therefore the density of observations is always identical on either side of the cut-off.

\subsection{Russell 3000 Cut-off}

Finally, we repeat our analyses for the stocks around the lower cut-off of the Russell 2000; i.e., stocks ranked above and below 3000. Here our sample period is restricted to 2005 onwards because the Russell 3000E, which includes roughly 4,000 stocks in the U.S. market and allows us to identify the firm rankings around the lower cut-off, is not available until 2005. Table 8 reports the results of a fuzzy RD design for the addition and deletion effects 
using a bandwidth of 100 and a local linear specification on either side of the cut-off. We do not see any significant addition effects. The coefficient for June is 0.036 with a t-statistic of 1.45 . This is not economically small. Our interpretation is that we do not have enough observations in the bottom cut-off given our data limitations.

We see a similar coefficient of 0.033 with a t-statistic of 1.25 for the deletion effect in June. What is interesting here is that we start getting significant effects for July and September, with excess returns of around 0.055 and t-statistics of around 2. We also see a large reversal in August of -0.054 , though this coefficient is not significant. We attribute this bouncing around of estimates to a lack of data. It might also be due to illiquidity in the bottom end of the index and the rebalancing delay of indexers. The data limitations make any causative attribution difficult.

In Table 9, we find a similar increase in correlation for index membership to that observed for the 1000 cut-off. The economic effects are quite significant with coefficients for July, August and September of around 0.25 and all highly significant. We see a similar strong covariance effect of membership in the Russell 2000 when we consider the deletion effects and the coefficients are similar in magnitude.

As before, there are no price volatility effects. However, we see some improvement in liquidity for added stocks, which differs from the results for the upper cut-off. This is perhaps due to the fact that these lower cut-off stocks are much smaller and hence more illiquid to begin with. We again find a large response in trading volume for firms that switched indices. Interestingly, there is a pronounced increase in the short ratio following both addition and deletion. Perhaps this strong response in short interest ratio around the bottom cut-off dampens some of the price effects of addition. Manipulation by hedge funds is more of a concern for this experiment. We test for differences in pre-reconstitution attributes in Table 10 but find no evidence of discontinuities in any measures. 


\section{Conclusion}

In this paper, we show that portfolio indexing can by analyzed using a regression discontinuity design for the Russell 2000. In contrast to the earlier approach associated with the S\&P 500, our use of the quantitative and transparent nature of the Russell 2000 index yields a much clearer identification strategy and fundamentally different findings from the existing literature. Namely, our randomization around the 1000 and 3000 cut-offs of the Russell Indices is not subject to the news critique of Denis, McConnell, Ovtchinnikov, and Yu (2003) that affects the S\&P 500 index. We find price effects for both addition and deletion. In contrast, the old S\&P 500 methodology finds only an addition effect, which is more consistent with a recognition or an earnings news effect than an indexing effect. We find that the price effects are accompanied by higher trading volume. Membership also gradually leads to elevated correlation of member stocks with the index and more short interest in stocks. In short, our regression discontinuity design provides a novel approach to measuring the impact of indexing on various features of stocks and firms, which might be of interest in other contexts in finance. 


\section{References}

Amihud, Y., 2002, "Illiquidity and stock returns: cross-section and time-series effects," Journal of Financial Markets, 5(1), 31-56.

Barber, B. M., and T. Odean, 2008, "All That Glitters: The Effect of Attention and News on the Buying Behavior of Individual and Institutional Investors," Review of Financial Studies, 21(2), 785-818.

Barberis, N., A. Shleifer, and J. Wurgler, 2005, "Comovement," Journal of Financial Economics, 75(2), 283-317.

Basak, S., and A. Pavlova, 2012, "Asset Prices and Institutional Investors," CEPR Discussion Papers 9120, C.E.P.R. Discussion Papers.

Beneish, M. D., and R. E. Whaley, 1996, "An Anatomy of the 'S\&P Game': The Effects of Changing the Rules," Journal of Finance, 51(5), 1909-30.

Boyer, B. H., 2011, "StyleRelated Comovement: Fundamentals or Labels?," Journal of Finance, 66(1), 307-332.

Campbell, J. Y., S. J. Grossman, and J. Wang, 1993, "Trading Volume and Serial Correlation in Stock Returns," The Quarterly Journal of Economics, 108(4), 905-39.

Campello, M., and J. R. Graham, 2013, "Do stock prices influence corporate decisions? Evidence from the technology bubble," Journal of Financial Economics, 107(1), 89-110.

Chen, H., G. Noronha, and V. Singal, 2004, "The Price Response to S\&P 500 Index Additions and Deletions: Evidence of Asymmetry and a New Explanation," Journal of Finance, 59(4), 1901-1930.

Denis, D. K., J. J. McConnell, A. V. Ovtchinnikov, and Y. Yu, 2003, "S\&P 500 Index Additions and Earnings Expectations," Journal of Finance, 58(5), 1821-1840. 
Gao, X., and J. R. Ritter, 2010, "The marketing of seasoned equity offerings," Journal of Financial Economics, 97(1), 33-52.

Greenwood, R., 2008, "Excess Comovement of Stock Returns: Evidence from Cross-Sectional Variation in Nikkei 225 Weights," Review of Financial Studies, 21(3), 1153-1186.

Grossman, S. J., and M. H. Miller, 1988, "Liquidity and Market Structure," Journal of Finance, 43(3), 617-37.

Hahn, J., P. Todd, and W. V. der Klaauw, 2001, "Identification and Estimation of Treatment Effects with a Regression-Discontinuity Designs," Econometrica, 69(1), 201-209.

Harris, L. E., and E. Gurel, 1986, "Price and Volume Effects Associated with Changes in the S\&P 500 List: New Evidence for the Existence of Price Pressures," Journal of Finance, $41(4), 815-29$.

Hirshleifer, D., S. S. Lim, and S. H. Teoh, 2009, "Driven to Distraction: Extraneous Events and Underreaction to Earnings News," Journal of Finance, 64(5), 2289-2325.

Lee, D. S., and T. Lemieux, 2010, "Regression Discontinuity Designs in Economics," Journal of Economic Literature, 48(2), 281-355.

Lynch, A. W., and R. R. Mendenhall, 1997, "New Evidence on Stock Price Effects Associated with Changes in the S\&P 500 Index," The Journal of Business, 70(3), 351-83.

McCrary, J., 2008, "Manipulation of the Running Variable in the Regression Discontinuity Design: A Density Test," Journal of Econometrics, 142(2), 698-714.

Merton, R. C., 1987, "A Simple Model of Capital Market Equilibrium with Incomplete Information," Journal of Finance, 42(3), 483-510.

Petajisto, A., 2011, "The index premium and its hidden cost for index funds," Journal of Empirical Finance, 18(2), 271-288. 
Shleifer, A., 1986, "Do Demand Curves for Stocks Slope Down?," Journal of Finance, 41(3), 579-90.

Vayanos, D., and P. Woolley, 2011, "Fund Flows and Asset Prices: A Baseline Model," FMG Discussion Papers dp667, Financial Markets Group.

Wurgler, J., and E. Zhuravskaya, 2002, "Does Arbitrage Flatten Demand Curves for Stocks?," The Journal of Business, 75(4), 583-608. 
Figure 1: May Market Capitalization Around Upper Cutoff

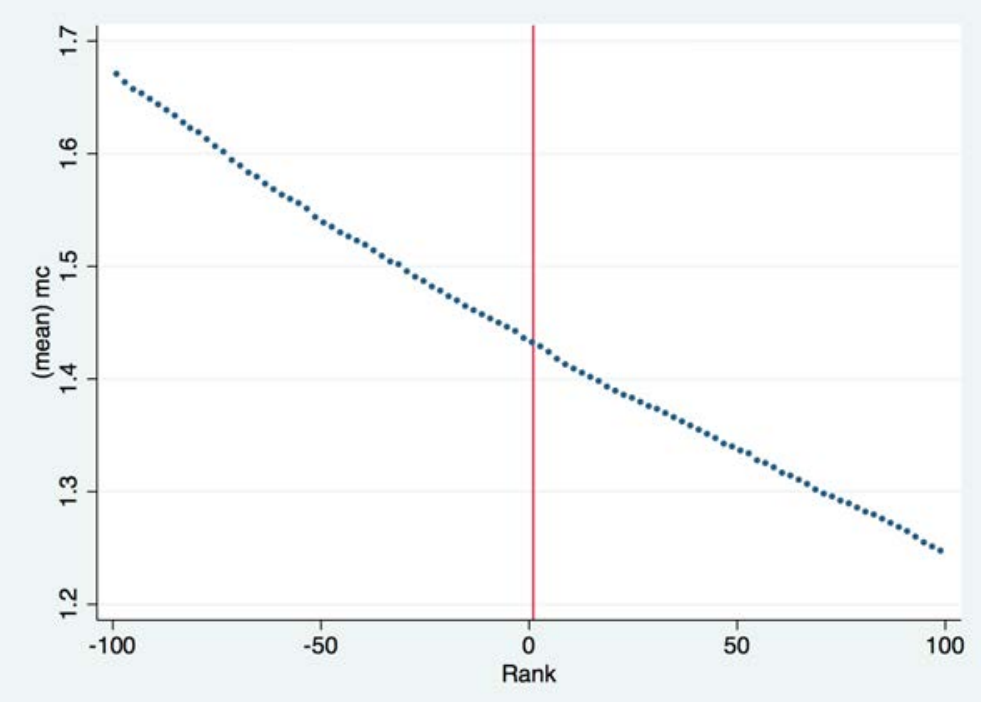

(a) Pre-Banding

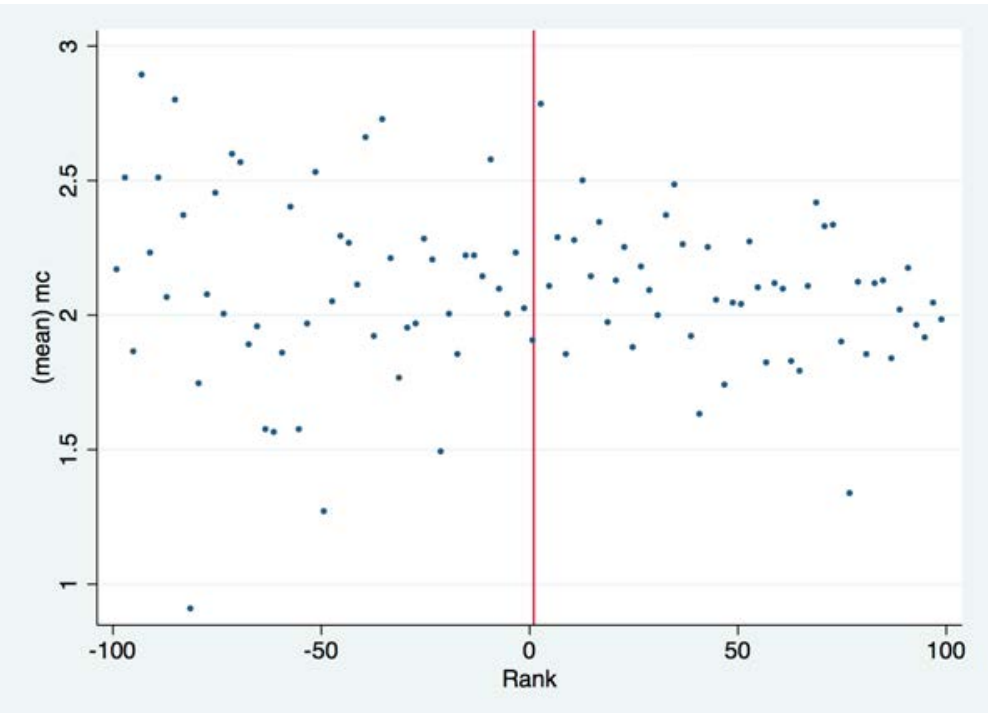

(b) Post-Banding

Note: May market capitalizations measured in billions of dollars are plotted against May rankings. The firms that will end up in the Russell 1000 are on the left hand side of the cutoff and the firms that will end up in the Russell 2000 are on the right hand side. The sample period is 1996-2006 for the pre-banding period and 2007-2012 for the post-banding period . 
Figure 2: May Market Capitalization Around Lower Cutoff

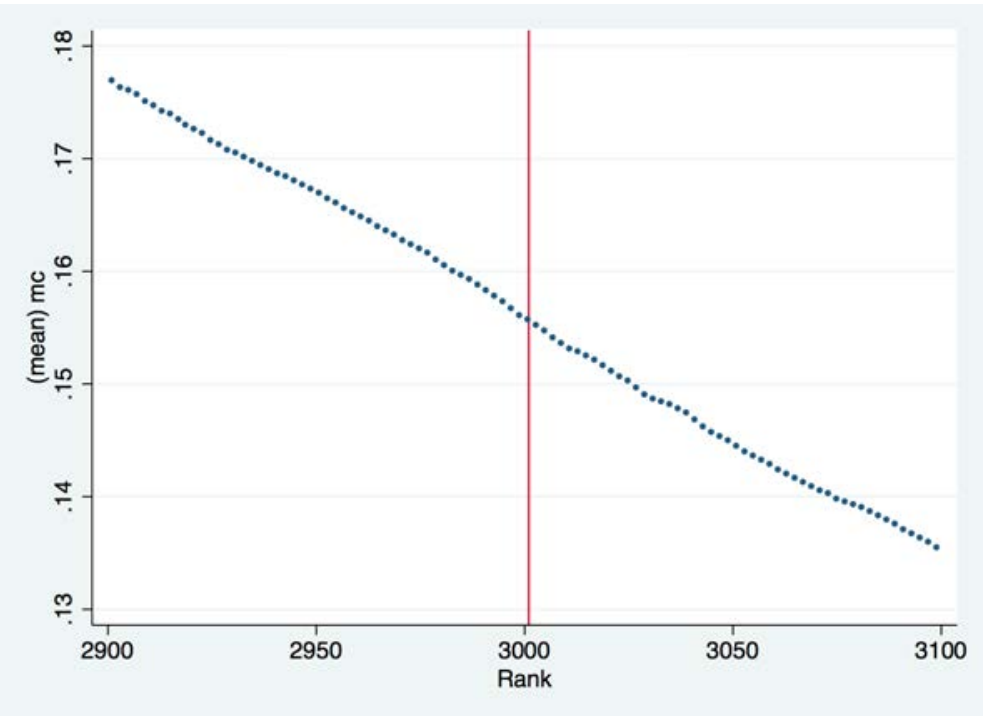

Note: May market capitalizations measured in billions of dollars are plotted against May rankings. The firms that will end up in the Russell 2000 are on the left hand side of the cutoff and the firms that will be deleted from the Russell 2000 are on the right hand side. The sample period is from 2005 through 2012. 
Figure 3: Index Weights for Firms Starting in the Russell 1000

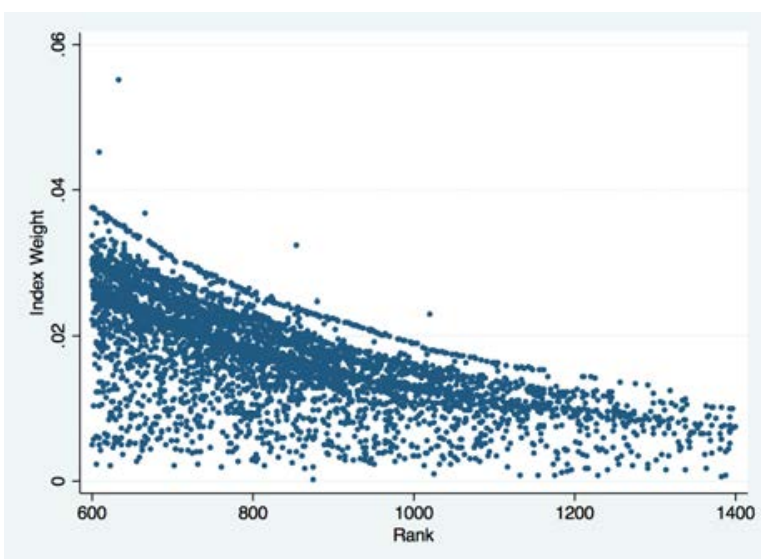

(a) May Weights

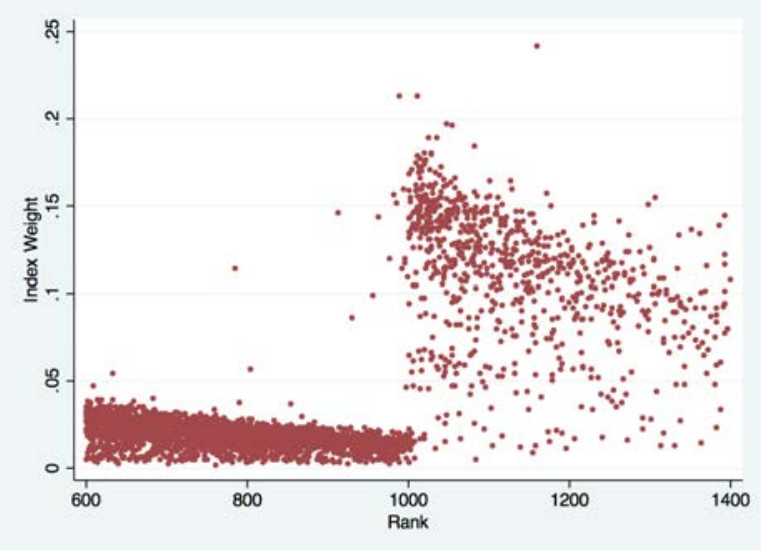

(b) June Weights

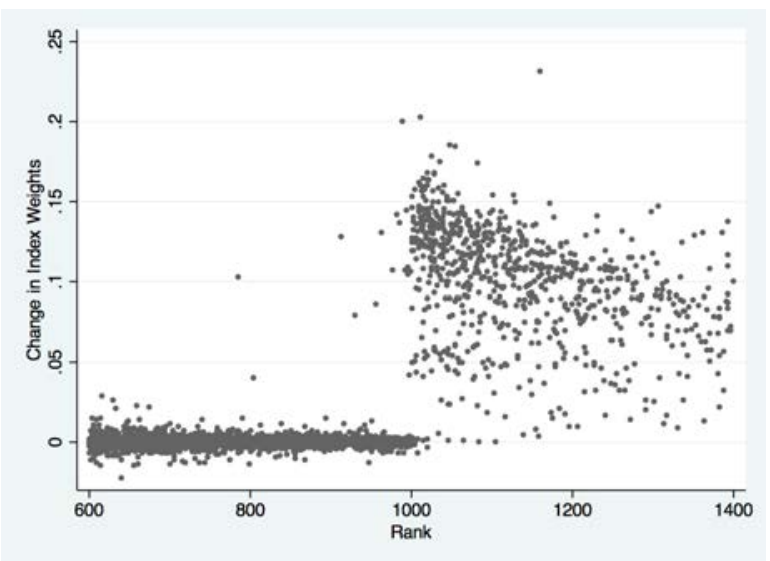

(c) Change from May to June

Note: Index weights are plotted against May market capitalization rankings. All firms shown were in the Russell 1000 index in May. June index weights refer to the firm's weight in whichever index it belongs to in June. The firms that stay in the Russell 1000 are on the left hand side of the cutoff. The firms that move into the Russell 2000 are on the right hand side. These are the firms that identify the addition effect. The sample period is from 1996 through 2006. 
Figure 4: Index Weights for Firms Starting in the Russell 2000

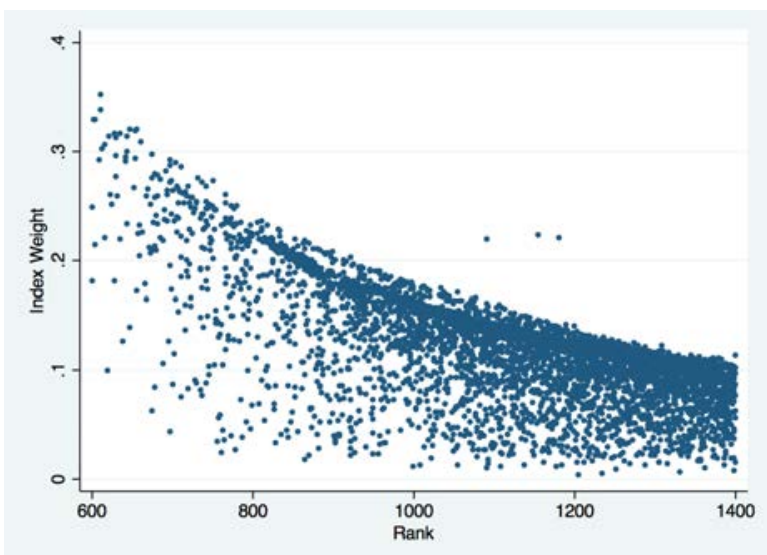

(a) May Weights

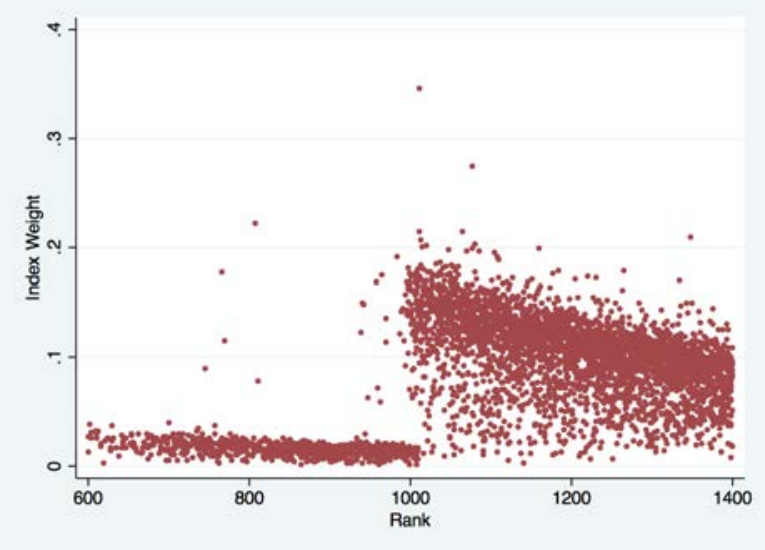

(b) June Weights

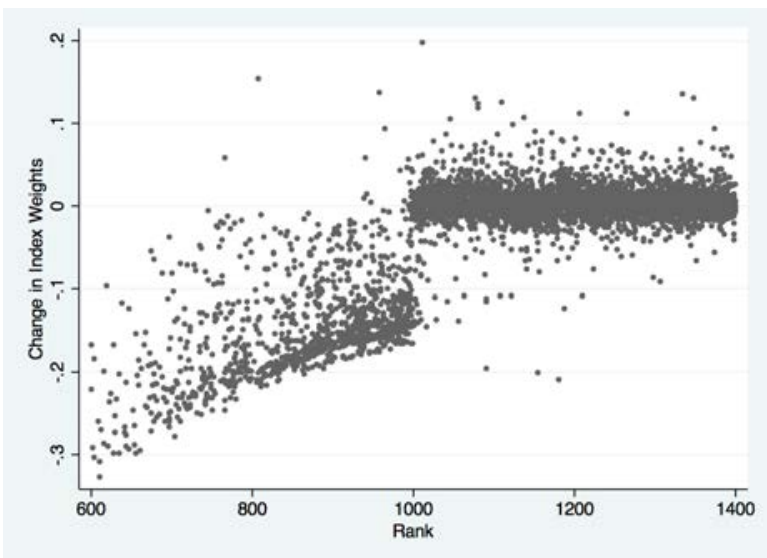

(c) Change from May to June

Note: Index weights are plotted against May market capitalization rankings. All firms shown were in the Russell 2000 index in May. June index weights refer to the firm's weight in whichever index it belongs to in June. The firms that moved into the Russell 1000 are on the left hand side of the cutoff. These are the firms that identify the deletion effect. The firms that stayed in the Russell 2000 are on the right hand side. The sample period is from 1996 through 2006. 
Figure 5: Index Weights for Firms Starting in the Russell 1000 - After Banding

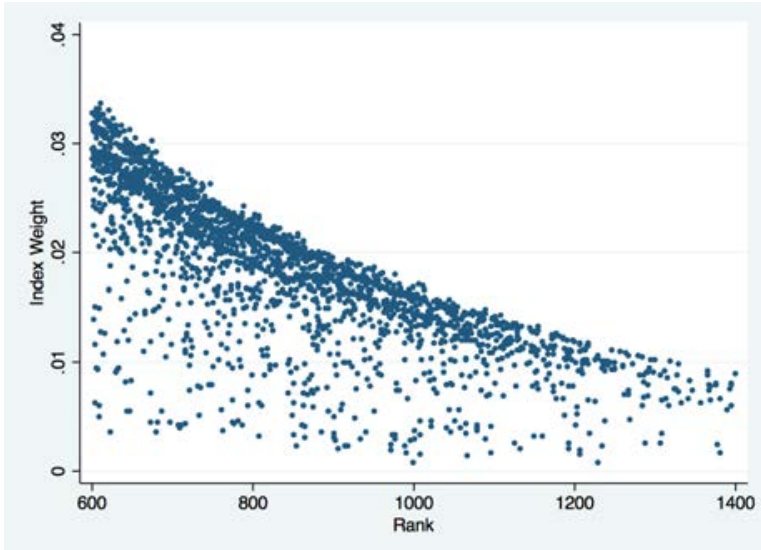

(a) May Weights

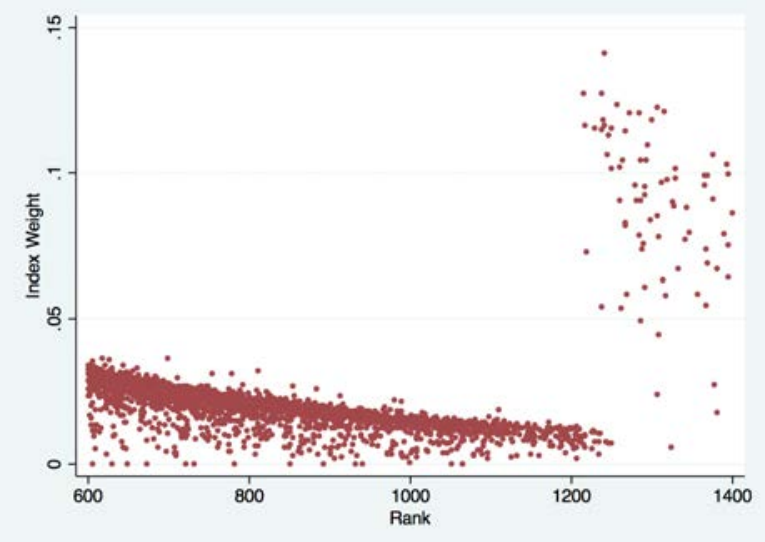

(b) June Weights

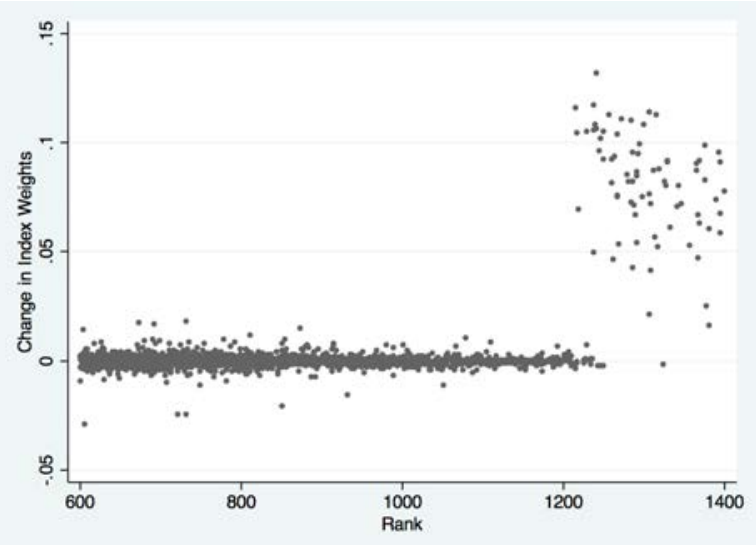

(c) Change from May to June

Note: Index weights are plotted against May market capitalization rankings. All firms shown were in the Russell 1000 index in May. June index weights refer to the firm's weight in whichever index it belongs to in June. The sample period is from 2007 through 2010. 
Figure 6: Index Weights for Firms Starting in the Russell 2000 - After Banding

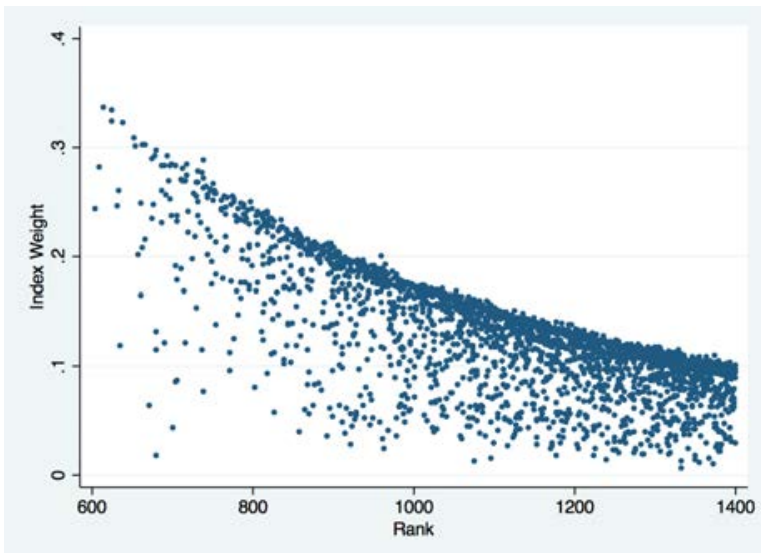

(a) May Weights

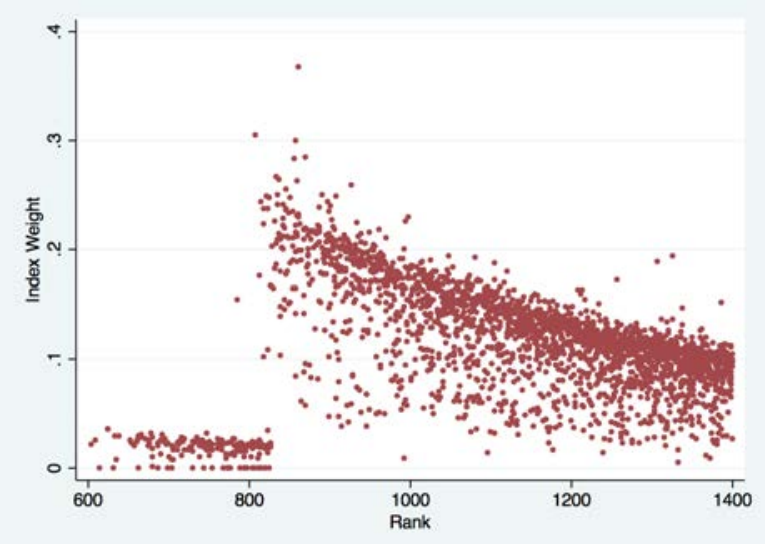

(b) June Weights

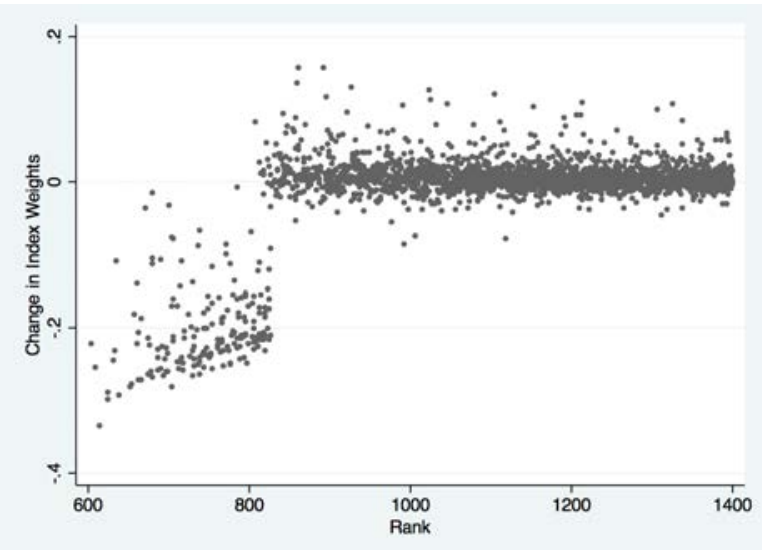

(c) Change from May to June

Note: Index weights are plotted against May market capitalization rankings. All firms shown were in the Russell 2000 index in May. June index weights refer to the firm's weight in whichever index it belongs to in June. The sample period is from 2007 through 2010. 
Figure 7: Index Weights Around Lower Cutoff for Firms Starting out of the Russell Index

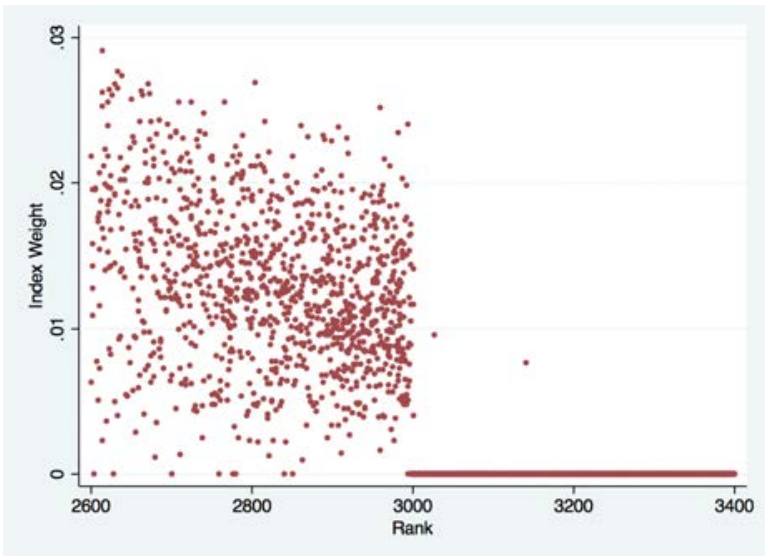

(a) June Weights

Note: Index weights are plotted against May market capitalization rankings. All firms shown were out of the Russell 2000 index in May. June index weights refer to the firm's weight in the Russell 2000 index in June and takes the value 0 if it was not a member of the index. The firms that move into the Russell 2000 are on the left hand side of the cutoff. These are the firms that identify the addition effect. The firms that stay out of the Russell 2000 are on the right hand side. The sample period is from 2005 through 2012. 
Figure 8: Index Weights Around Lower Cutoff for Firms Starting in the Russell 2000

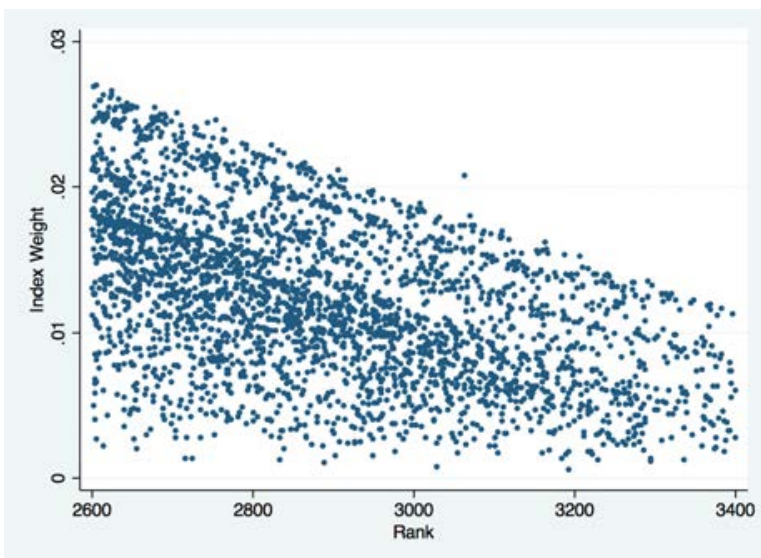

(a) May Weights

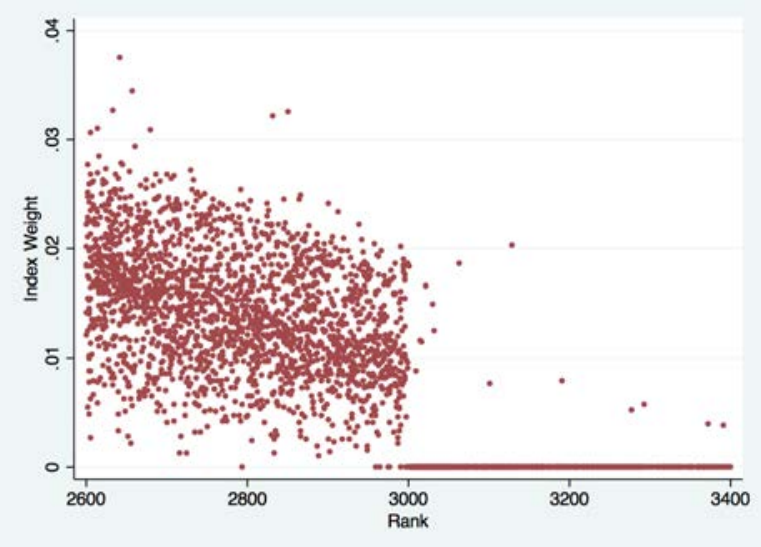

(b) June Weights

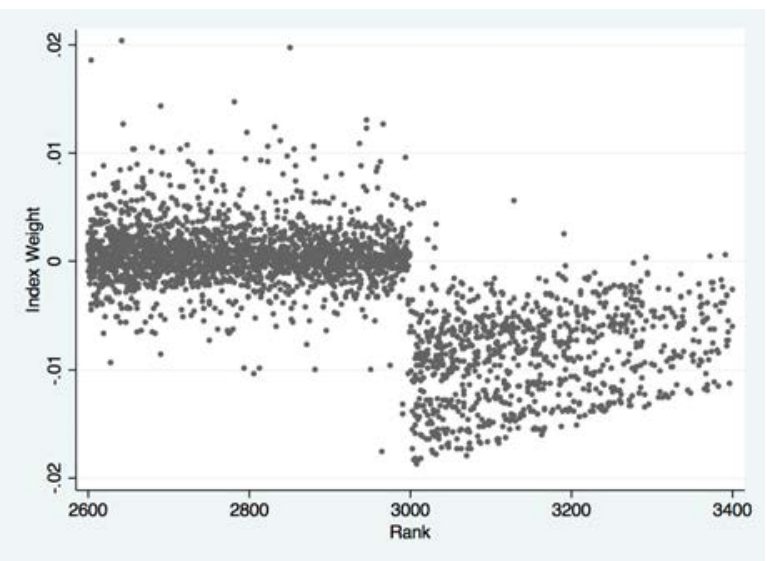

(c) Change from May to June

Note: Index weights are plotted against May market capitalization rankings. All firms shown were in the Russell 2000 index in May. June index weights refer to the firm's weight in the Russell 2000 index in June and takes the value 0 if it was not a member of the index. The firms that stay in the Russell 2000 are on the left hand side of the cutoff. The firms that move out of the Russell 2000 are on the right hand side. These are the firms that identify the deletion effect. The sample period is from 2005 through 2012. 


\section{Figure 9: June Returns Around Upper Cutoff - Addition Effect}

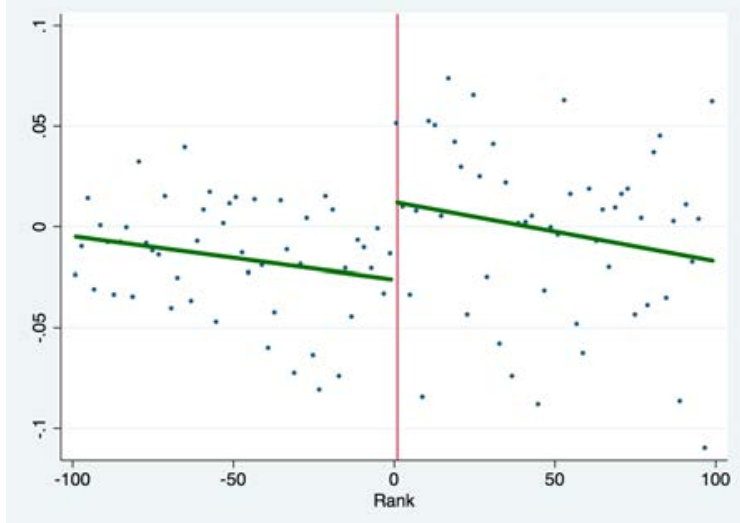

(a) Bin Width $=2$

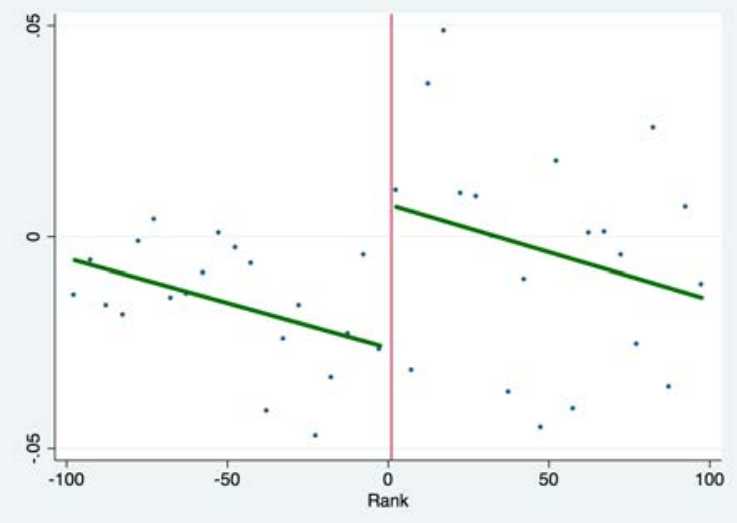

(b) Bin Width $=5$

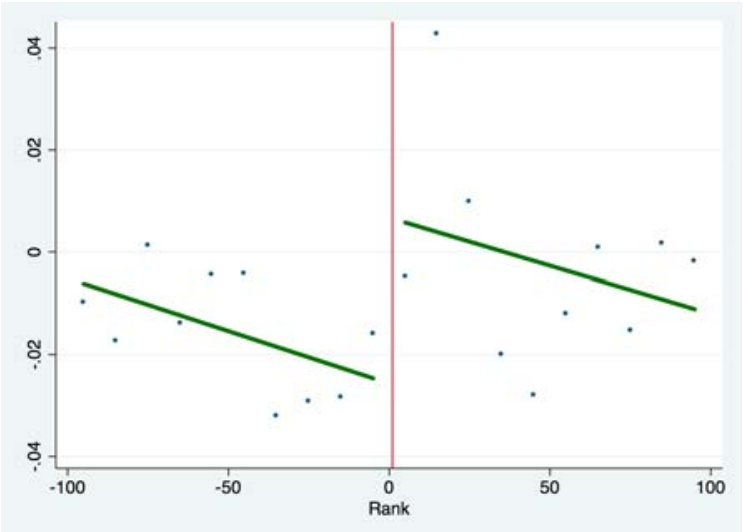

(c) Bin Width $=10$

Note: June returns are plotted against market capitalization ranking. All firms shown were in the Russell 1000 index in May. The firms that stay in the Russell 1000 are on the left hand side of the cutoff. The firms that move into the Russell 2000 are on the right hand side. These are the firms that identify the addition effect. The sample period is from 1996 through 2012. The lines drawn fit linear functions of rank on either side of the cutoff. 
Figure 10: June Returns Around Upper Cutoff - Deletion Effect

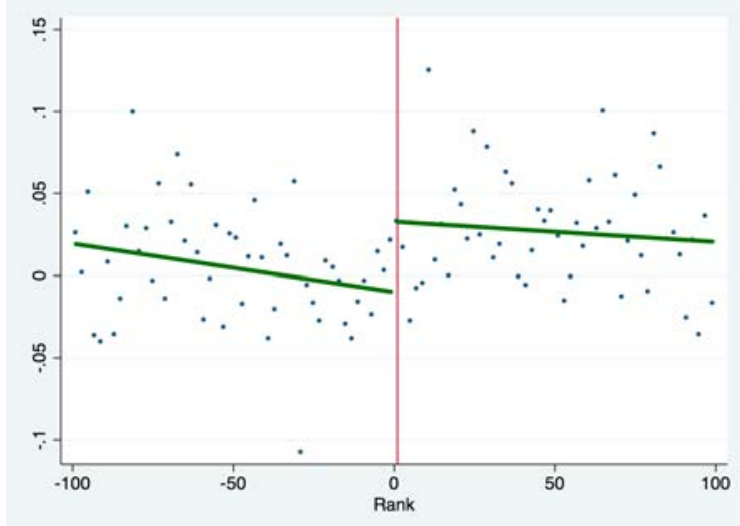

(a) Bin Width $=2$

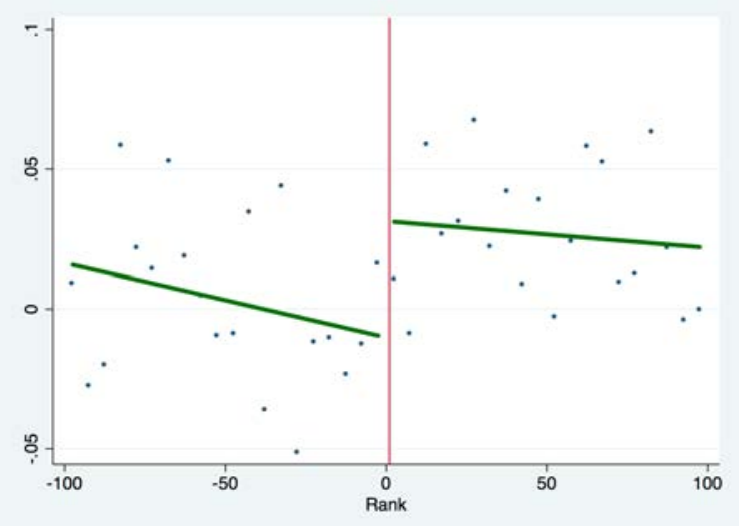

(b) Bin Width $=5$

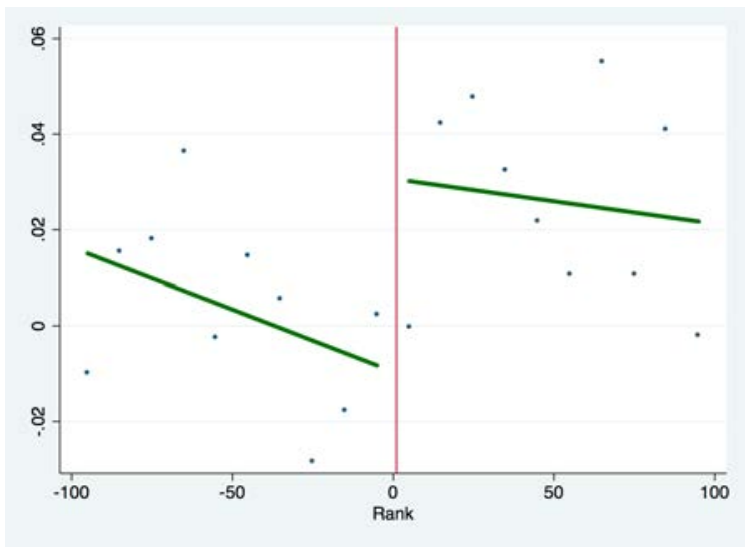

(c) Bin Width $=10$

Note: June returns are plotted against market capitalization ranking. All firms shown were in the Russell 2000 index in May. The firms that moved into the Russell 1000 are on the left hand side of the cutoff. These are the firms that identify the deletion effect. The firms that stayed in the Russell 2000 are on the right hand side. The sample period is from 1996 through 2012. The lines drawn fit linear functions of rank on either side of the cutoff. 
Figure 11: Validity Tests Around Upper Cutoff

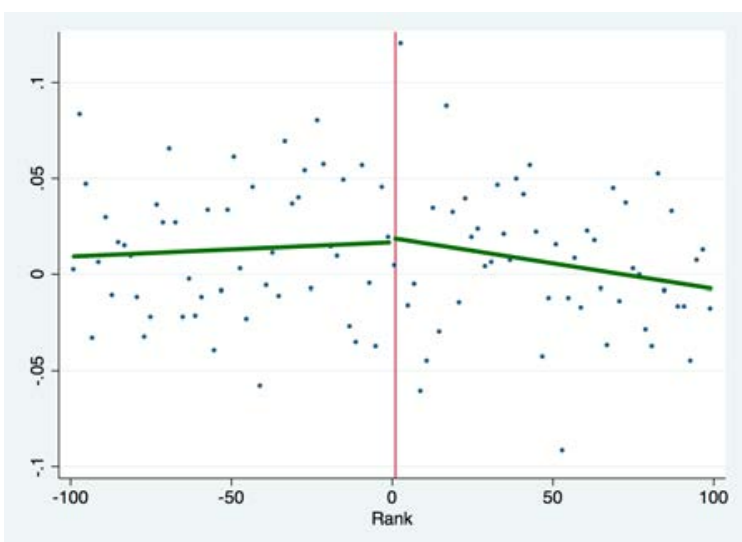

(a) May Returns - Addition

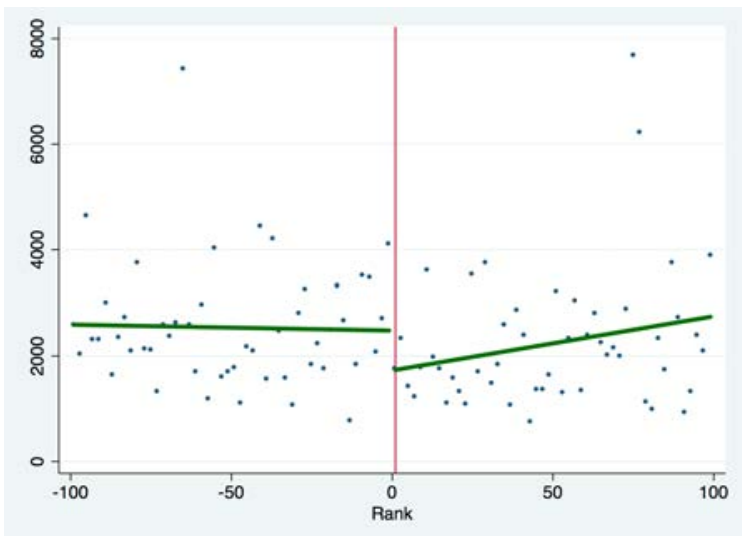

(c) Assets - Addition

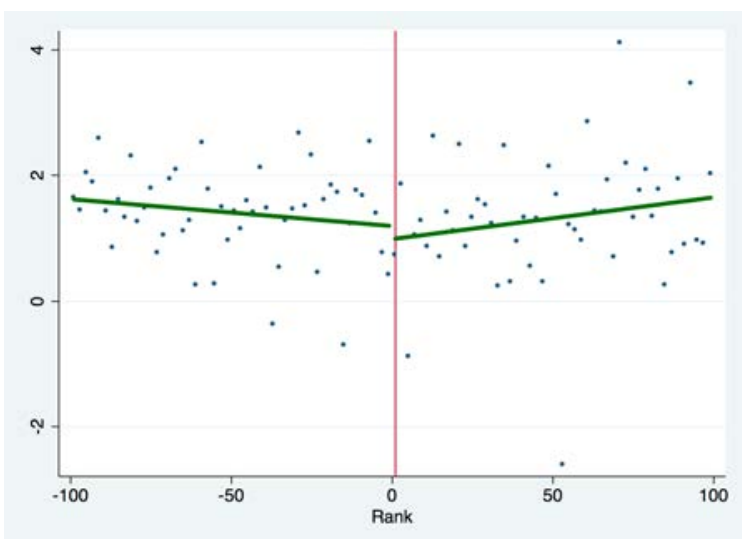

(e) EPS - Addition

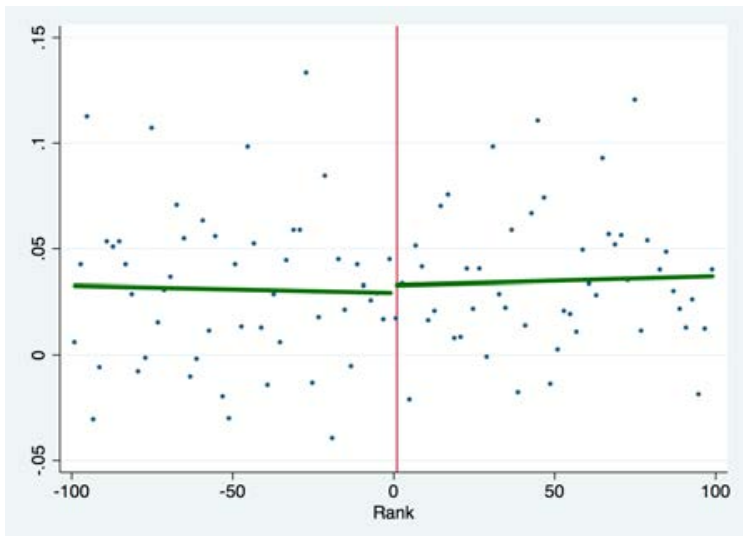

(b) May Returns - Deletion

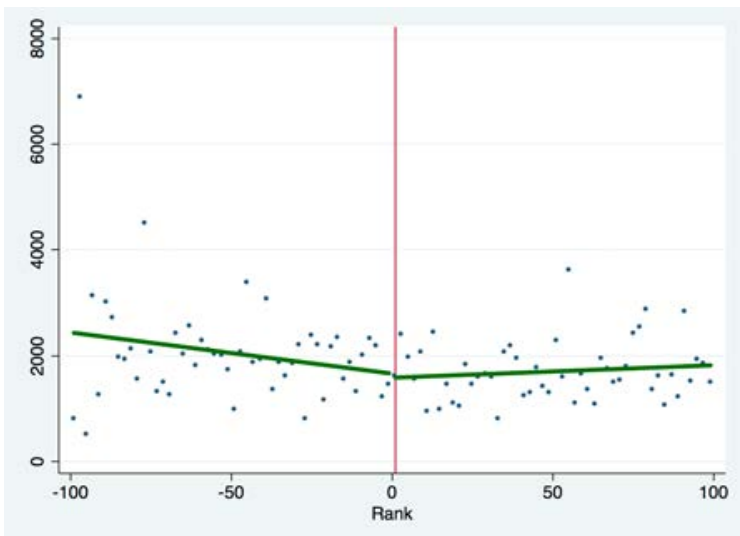

(d) Assets - Deletion

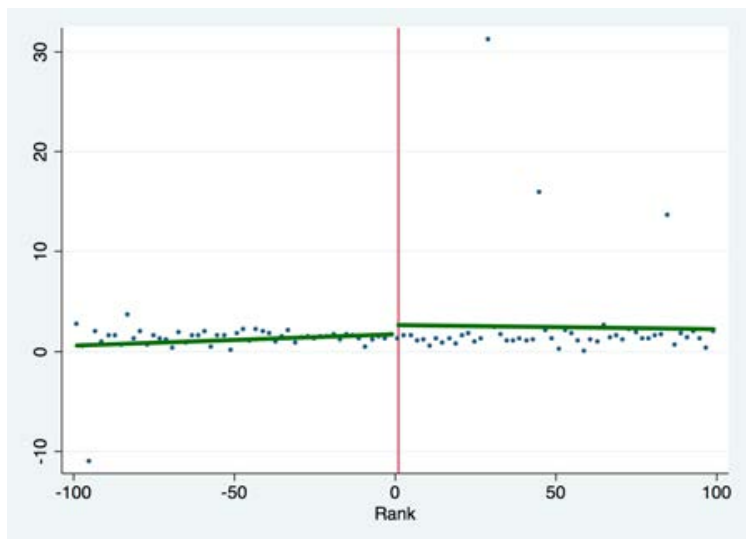

(f) EPS - Deletion

Note: Outcome variables are plotted against market capitalization ranking. The firms that ended up in the Russell 1000 are on the left hand side of the cutoff. The firms that ended up in the Russell 2000 are on the right hand side. The sample period is from 1996 through 2012. The lines drawn fit linear functions of rank on either side of the cutoff. 
Table 1: Assets Benchmarked to Indices

Panel A: Passive Assets

\begin{tabular}{ccccccccc}
\hline \hline & 1996 & 1997 & 1998 & 1999 & 2000 & 2001 & 2002 & 2003 \\
\hline Russell 2000 & 11.6 & 7.6 & 11.0 & 13.6 & 18.9 & 21.5 & 26.9 & 24.6 \\
Russell 1000 & 20.9 & 20.7 & 19.0 & 25.9 & 17.3 & 34.0 & 35.6 & 37.2 \\
\hline & & & & & & & & \\
\hline & 2004 & 2005 & 2006 & 2007 & 2008 & 2009 & 2010 & 2011 \\
\hline Russell 2000 & 38.9 & 39.2 & 43.0 & 51.7 & 38.5 & 38.4 & 56.8 & 60.1 \\
Russell 1000 & 84.9 & 93.3 & 151.9 & 175.8 & 144.8 & 104.4 & 137.1 & 125.8 \\
\hline
\end{tabular}

Panel B: Assets Benchmarked

\begin{tabular}{cccccccc}
\hline \hline Number of Products & 2002 & 2003 & 2004 & 2005 & 2006 & 2007 & 2008 \\
\hline S\&P 500 & 1,009 & 924 & 919 & 901 & 888 & 824 & 685 \\
Russell 2000 & 289 & 255 & 264 & 275 & 273 & 511 & 449 \\
Russell 1000 & 29 & 43 & 43 & 48 & 52 & 52 & 60 \\
\hline Dollar Amount & 2002 & 2003 & 2004 & 2005 & 2006 & 2007 & 2008 \\
\hline S\&P 500 & $1,679.8$ & $1,096.9$ & $1,431.8$ & $1,482.9$ & $1,576.7$ & $1,748.6$ & $1,412.1$ \\
Russell 2000 & 198.2 & 140.7 & 162.5 & 201.4 & 221.1 & 291.4 & 263.7 \\
Russell 1000 & 47.6 & 37.3 & 66.9 & 90.0 & 146.1 & 172.7 & 168.6 \\
\hline
\end{tabular}

Note: Panel A reports the dollar amount of passive assets, in billions, benchmarked to Russell 1000 and Russell 2000 by year from Russell's internal unaudited survey of its clients at the end of June. Panel B reports the number of products and dollar amount (in billions) of institutional assets benchmarked to Russell 2000, Russell 1000, and S\&P 500. These numbers are taken from Russell Investment's 2008 US Equity Indexes: Institutional Benchmark Survey. The products surveyed are primarily institutional-oriented mutual funds, separate accounts, and commingled funds at the end of May. 
Table 2: Summary Statistics

\begin{tabular}{|c|c|c|c|c|c|c|}
\hline & \multicolumn{3}{|c|}{ Russell 1000} & \multicolumn{3}{|c|}{ Russell 2000} \\
\hline & Median & Mean & StDev & Median & Mean & StDev \\
\hline RET & 0.007 & 0.008 & 0.122 & 0.007 & 0.014 & 0.162 \\
\hline MKTCAP & 4.220 & 12.000 & 26.300 & 0.516 & 0.658 & 0.496 \\
\hline CORR2000 & 0.475 & 0.441 & 0.261 & 0.466 & 0.436 & 0.259 \\
\hline VOL & 0.019 & 0.023 & 0.015 & 0.026 & 0.031 & 0.019 \\
\hline ILLIQ & 0.053 & 0.180 & 1.370 & 1.020 & 4.570 & 20.900 \\
\hline IO & 0.722 & 0.701 & 0.201 & 0.642 & 0.665 & 6.190 \\
\hline VR & 0.967 & 1.050 & 0.449 & 0.949 & 1.100 & 0.856 \\
\hline ISSUANCE & 0.014 & 0.232 & 17.10 & 0.024 & 0.116 & 13.10 \\
\hline SR & 0.023 & 0.037 & 0.043 & 0.033 & 0.053 & 0.064 \\
\hline REP & 1.000 & 0.683 & 0.465 & 0.000 & 0.477 & 0.499 \\
\hline $\mathrm{ROE}$ & 0.133 & 0.093 & 4.430 & 0.093 & -1.770 & 203 \\
\hline $\mathrm{ROA}$ & 0.046 & 0.042 & 0.150 & 0.035 & -0.001 & 0.217 \\
\hline EPS & 1.690 & 1.780 & 4.340 & 0.840 & 0.717 & 4.240 \\
\hline ASSET & 4,805 & 21,449 & 86,939 & 604 & 1,079 & 1,873 \\
\hline $\mathrm{C} / \mathrm{A}$ & 0.038 & 0.071 & 0.086 & 0.051 & 0.100 & 0.126 \\
\hline ICR & 6.090 & 73.300 & 1,127 & 4.160 & 72.400 & 1,537 \\
\hline FLOAT & 112,252 & 289,129 & 638,581 & 21,961 & 29,326 & 31,097 \\
\hline Observations & 55842 & & & 91198 & & \\
\hline
\end{tabular}

Note: This table reports monthly summary statistics for all member stocks in the Russell 1000 and Russell 2000. RET is monthly stock returns. MKTCAP is in billions of dollars. CORR2000 is the correlation between daily stock returns and Russell 2000 index returns, computed monthly. VOL is the standard deviation in daily stock returns, computed monthly. ILLIQ is the Amihud (2002) illiquidity measure, in percentage per million-dollar volume. IO is institutional ownership. VR is volume ratio. ISSUANCE is the ratio of shares issued in that fiscal year to initial shares. SR is short ratio. REP is an indicator for repurchase activity in that fiscal year. EPS is the earnings per share, excluding extraordinary items. ASSET is asset book value in millions of dollars. C/A is the cash to asset ratio. ICR is the interest coverage ratio. FLOAT is the number of floating shares (in thousands). The sample period is 1996-2012. 


\section{Table 3: First Stage of Fuzzy RD}

Addition Effect

\begin{tabular}{lccc}
\hline \hline & Upper Cutoff & Upper Cutoff After Banding & Lower Cutoff \\
\hline$\tau$ & $0.785^{* * *}$ & $0.820^{* * *}$ & $0.862^{* * *}$ \\
& $(31.50)$ & $(12.98)$ & $(48.86)$ \\
\hline$N$ & 893 & 164 & 837 \\
adj. $R^{2}$ & 0.863 & 0.845 & 0.933 \\
$\mathrm{~F}$ & 1,876 & 297 & 3,896 \\
\hline \hline
\end{tabular}

Deletion Effect

\begin{tabular}{lccc}
\hline \hline & Upper Cutoff & Upper Cutoff After Banding & Lower Cutoff \\
\hline$\tau$ & $0.705^{* * *}$ & $0.759^{* * *}$ & $0.865^{* * *}$ \\
& $(29.15)$ & $(20.90)$ & $(39.79)$ \\
\hline$N$ & 1206 & 340 & 771 \\
adj. $R^{2}$ & 0.817 & 0.878 & 0.910 \\
$\mathrm{~F}$ & 1,799 & 815 & 2,601 \\
\hline \hline
\end{tabular}

Note: The table reports the first stage regression from a fuzzy RD design. The outcome variable is an indicator for addition to the Russell 2000 index. The variable $\tau$ is an indicator for whether the firm's rank predicted addition to the Russell 2000 index. T-statistics are reported in parentheses. All regressions use firms with end-of-May ranking within 100 spots of the predicted cut-off. The regression specification is linear in ranking by market capitalization on either side of the cut-off. The panel identifying the addition effect only uses firms that were not in the Russell 2000 at the end of May. The panel identifying the deletion effect only uses firms that were members of the Russell 2000 at the end of May.

${ }^{*} \mathrm{p}<0.05,{ }^{* *} \mathrm{p}<0.01,{ }^{* * *} \mathrm{p}<0.001$ 
Table 4: Returns Fuzzy RD - Addition Effect

\begin{tabular}{cccccc}
\multicolumn{7}{c}{ Bandwidth $=50$} \\
\hline \hline & May & Jun & Jul & Aug & Sep \\
\hline $\mathrm{p}=1$ & -0.010 & $0.110^{* *}$ & 0.041 & -0.031 & 0.001 \\
& $(-0.27)$ & $(3.13)$ & $(1.04)$ & $(-0.76)$ & $(0.02)$ \\
\hline $\mathrm{p}=2$ & 0.005 & 0.061 & 0.180 & -0.138 & -0.006 \\
& $(0.04)$ & $(0.60)$ & $(1.23)$ & $(-1.03)$ & $(-0.04)$ \\
\hline$N$ & 533 & 533 & 531 & 530 & 527 \\
\hline \hline
\end{tabular}

\begin{tabular}{cccccc}
\multicolumn{7}{c}{ Bandwidth $=100$} \\
\hline \hline & May & Jun & Jul & Aug & Sep \\
\hline $\mathrm{p}=1$ & -0.003 & $0.050^{* *}$ & -0.003 & 0.035 & -0.021 \\
& $(-0.14)$ & $(2.65)$ & $(-0.11)$ & $(1.59)$ & $(-0.89)$ \\
\hline $\mathrm{p}=2$ & -0.029 & $0.110^{* *}$ & 0.085 & -0.016 & 0.014 \\
& $(-0.68)$ & $(2.73)$ & $(1.78)$ & $(-0.35)$ & $(0.29)$ \\
\hline$N$ & 1055 & 1057 & 1053 & 1052 & 1047 \\
\hline \hline
\end{tabular}

Bandwidth $=200$

\begin{tabular}{cccccc}
\hline \hline & May & Jun & Jul & Aug & Sep \\
\hline $\mathrm{p}=1$ & -0.012 & 0.022 & -0.000 & 0.027 & -0.015 \\
& $(-0.92)$ & $(1.84)$ & $(-0.02)$ & $(1.88)$ & $(-1.08)$ \\
\hline $\mathrm{p}=2$ & -0.011 & $0.060^{* *}$ & 0.001 & 0.013 & -0.023 \\
& $(-0.47)$ & $(2.86)$ & $(0.05)$ & $(0.55)$ & $(-0.89)$ \\
\hline$N$ & 2253 & 2255 & 2245 & 2231 & 2222 \\
\hline \hline
\end{tabular}

\begin{tabular}{cccccc}
\multicolumn{7}{c}{ Bandwidth $=300$} \\
\hline \hline & May & Jun & Jul & Aug & Sep \\
\hline $\mathrm{p}=1$ & -0.002 & 0.009 & -0.013 & 0.009 & -0.000 \\
& $(-0.18)$ & $(0.91)$ & $(-1.07)$ & $(0.76)$ & $(-0.04)$ \\
\hline $\mathrm{p}=2$ & -0.007 & $0.036^{*}$ & 0.019 & $0.039^{*}$ & -0.023 \\
& $(-0.38)$ & $(2.23)$ & $(0.94)$ & $(2.08)$ & $(-1.20)$ \\
\hline$N$ & 3532 & 3534 & 3516 & 3491 & 3477 \\
\hline \hline
\end{tabular}

Note: The table reports the results of a fuzzy RD design. The outcome variable is monthly stock returns and the dependent variable is an indicator for addition to the Russell 2000 index. Monthly returns are shown for the month immediately preceding the index rebalancing (June) and for four months after. T-statistics are reported in parentheses. The bandwidth specifies the range of firms that was included on either side of the cut-off. For each bandwidth, the RD estimate is shown use both a linear $(\mathrm{p}=1)$ and quadratic $(\mathrm{p}=2)$ polynomial in firm ranking that is allowed to vary on either sides of the cut-off. Only firms that were members of the Russell 1000 index at the end of May are used. The sample period is 1996-2012.

${ }^{*} \mathrm{p}<0.05,{ }^{* *} \mathrm{p}<0.01,{ }^{* * *} \mathrm{p}<0.001$ 
Table 5: Returns Fuzzy RD - Deletion Effect

\begin{tabular}{cccccc}
\multicolumn{7}{c}{ Bandwidth $=50$} \\
\hline \hline & May & Jun & Jul & Aug & Sep \\
\hline $\mathrm{p}=1$ & -0.010 & 0.052 & 0.015 & -0.006 & 0.014 \\
& $(-0.31)$ & $(1.64)$ & $(0.40)$ & $(-0.20)$ & $(0.36)$ \\
\hline $\mathrm{p}=2$ & -0.034 & -0.050 & 0.212 & 0.006 & 0.064 \\
& $(-0.35)$ & $(-0.49)$ & $(1.46)$ & $(0.06)$ & $(0.48)$ \\
\hline$N$ & 763 & 762 & 755 & 751 & 746 \\
\hline \hline
\end{tabular}

\begin{tabular}{cccccc}
\multicolumn{7}{c}{ Bandwidth $=100$} \\
\hline \hline & May & Jun & Jul & Aug & Sep \\
\hline $\mathrm{p}=1$ & 0.005 & $0.054^{* *}$ & -0.019 & -0.002 & 0.011 \\
& $(0.32)$ & $(3.00)$ & $(-0.96)$ & $(-0.09)$ & $(0.53)$ \\
\hline $\mathrm{p}=2$ & -0.027 & 0.052 & 0.025 & -0.000 & 0.019 \\
& $(-0.81)$ & $(1.48)$ & $(0.60)$ & $(-0.00)$ & $(0.44)$ \\
\hline$N$ & 1546 & 1545 & 1533 & 1526 & 1519 \\
\hline \hline
\end{tabular}

\begin{tabular}{cccccc}
\multicolumn{6}{c}{ Bandwidth $=200$} \\
\hline \hline & May & Jun & Jul & Aug & Sep \\
\hline $\mathrm{p}=1$ & 0.010 & $0.044^{* * *}$ & -0.024 & -0.004 & 0.010 \\
& $(0.94)$ & $(3.97)$ & $(-1.90)$ & $(-0.33)$ & $(0.77)$ \\
\hline $\mathrm{p}=2$ & 0.007 & $0.053^{* *}$ & -0.014 & 0.003 & 0.005 \\
& $(0.37)$ & $(2.61)$ & $(-0.60)$ & $(0.14)$ & $(0.20)$ \\
\hline$N$ & 3027 & 3026 & 3003 & 2984 & 2974 \\
\hline \hline
\end{tabular}

\begin{tabular}{cccccc}
\multicolumn{6}{c}{ Bandwidth $=300$} \\
\hline \hline & May & Jun & Jul & Aug & Sep \\
\hline $\mathrm{p}=1$ & 0.010 & $0.029^{* * *}$ & -0.013 & 0.004 & 0.008 \\
& $(1.13)$ & $(3.29)$ & $(-1.43)$ & $(0.41)$ & $(0.84)$ \\
\hline $\mathrm{p}=2$ & 0.007 & $0.053^{* * *}$ & -0.027 & -0.009 & 0.012 \\
& $(0.51)$ & $(3.61)$ & $(-1.64)$ & $(-0.59)$ & $(0.69)$ \\
\hline$N$ & 4529 & 4528 & 4497 & 4467 & 4451 \\
\hline \hline
\end{tabular}

Note: The table reports the results of a fuzzy RD design. The outcome variable is monthly stock returns and the dependent variable is an indicator for staying in the Russell 2000 index. Monthly returns are shown for the month immediately preceding the index rebalancing (June) and for four months after. T-statistics are reported in parentheses. The bandwidth specifies the range of firms that was included on either side of the cut-off. For each bandwidth, the RD estimate is shown use both a linear $(\mathrm{p}=1)$ and quadratic $(\mathrm{p}=2)$ polynomial in firm ranking that is allowed to vary on both sides of the cut-off. Only firms that were members of the Russell 2000 index at the end of May are used. The sample period is 1996-2012.

${ }^{*} \mathrm{p}<0.05,{ }^{* *} \mathrm{p}<0.01,{ }^{* * *} \mathrm{p}<0.001$ 
Table 6: Other Outcome Variables

Addition Effect

\begin{tabular}{lccccc}
\hline \hline & May & Jun & Jul & Aug & Sep \\
\hline CORR 2000 & 0.034 & -0.033 & 0.047 & $0.122^{* *}$ & $0.092^{*}$ \\
& $(0.82)$ & $(-0.76)$ & $(1.10)$ & $(2.79)$ & $(2.04)$ \\
\hline VOL & -0.001 & 0.001 & -0.001 & 0.001 & -0.002 \\
& $(-0.52)$ & $(0.23)$ & $(-0.26)$ & $(0.24)$ & $(-0.69)$ \\
\hline ILLIQ & 0.558 & 0.429 & -0.033 & 0.004 & 0.136 \\
& $(0.82)$ & $(1.06)$ & $(-0.22)$ & $(0.02)$ & $(0.46)$ \\
\hline IO & & 0.031 & & & 0.036 \\
& & $(0.77)$ & & & $(0.89)$ \\
\hline VR & -0.010 & $0.478^{* *}$ & 0.114 & 0.097 & -0.020 \\
& $(-0.13)$ & $(3.14)$ & $(1.44)$ & $(1.15)$ & $(-0.22)$ \\
\hline ISSUANCE & & -0.395 & & & \\
& & $(-1.42)$ & & & \\
\hline SR & -0.001 & 0.002 & 0.007 & 0.002 & 0.005 \\
& $(-0.14)$ & $(0.20)$ & $(0.75)$ & $(0.22)$ & $(0.57)$ \\
\hline$N$ & 920 & 921 & 918 & 915 & 913 \\
\hline \hline
\end{tabular}

Deletion Effect

\begin{tabular}{lccccc}
\hline \hline & May & Jun & Jul & Aug & Sep \\
\hline CORR 2000 & -0.016 & $0.132^{* * *}$ & $0.200^{* * *}$ & 0.058 & $0.121^{* *}$ \\
& $(-0.43)$ & $(3.47)$ & $(5.06)$ & $(1.45)$ & $(3.01)$ \\
\hline VOL & 0.001 & 0.002 & 0.003 & 0.003 & $0.005^{*}$ \\
& $(0.37)$ & $(0.98)$ & $(1.11)$ & $(1.36)$ & $(2.02)$ \\
\hline ILLIQ & 0.085 & 0.005 & -0.105 & -0.743 & -0.216 \\
& $(0.11)$ & $(0.01)$ & $(-0.29)$ & $(-0.83)$ & $(-0.39)$ \\
\hline IO & & -0.063 & & & -0.037 \\
& & $(-1.69)$ & & & $(-1.02)$ \\
\hline VR & 0.151 & $-0.263^{* *}$ & 0.050 & 0.106 & 0.166 \\
& $(0.79)$ & $(-2.74)$ & $(0.55)$ & $(1.55)$ & $(1.64)$ \\
\hline ISSUANCE & & 0.115 & & & \\
& & $(0.44)$ & & & \\
\hline SR & 0.001 & -0.000 & 0.010 & 0.012 & 0.011 \\
& $(0.14)$ & $(-0.02)$ & $(1.16)$ & $(1.43)$ & $(1.31)$ \\
\hline$N$ & 1308 & 1309 & 1300 & 1295 & 1284 \\
\hline \hline
\end{tabular}

Note: The table reports the results of a fuzzy RD design. The dependent variable is an indicator for addition the Russell 2000 index. All regressions use firms with end-of-May ranking within 100 spots of the predicted cut-off. The regression specification is linear in ranking and is allowed to vary on either side of the cut-off. Only firms that were members of the Russell 1000 index at the end of May are used to estimate the addition effect. Only those that were members of the Russell 2000 are used for the deletion effect. Issuance is defined for the fiscal year. Definitions of fiscal year vary by company but always include the June following reconstitution. The sample period is 1996-2012.

${ }^{*} \mathrm{p}<0.05,{ }^{* *} \mathrm{p}<0.01,{ }^{* * *} \mathrm{p}<0.001$ 
Table 7: Validity Tests

Addition Effect

\begin{tabular}{cccccccccc}
\hline \hline & MKTCAP & REP & ROE & ROA & EPS & ASSETS & ICR & C/A & FLOAT \\
\hline & 0.003 & -0.055 & -1.243 & 0.069 & -0.042 & -789.443 & 18.737 & 0.021 & -786.479 \\
& $(0.06)$ & $(-0.59)$ & $(-0.37)$ & $(1.36)$ & $(-0.11)$ & $(-1.39)$ & $(0.22)$ & $(1.09)$ & $(-0.07)$ \\
\hline$N$ & 1057 & 747 & 887 & 887 & 886 & 888 & 782 & 866 & 1057 \\
\hline \hline
\end{tabular}

Deletion Effect

\begin{tabular}{cccccccccc}
\hline \hline & MKTCAP & REP & ROE & ROA & EPS & ASSETS & ICR & C/A & FLOAT \\
\hline & 0.031 & -0.053 & -0.927 & -0.025 & 0.898 & -89.741 & -159.523 & 0.009 & -2203.850 \\
& $(0.41)$ & $(-0.64)$ & $(-0.98)$ & $(-0.84)$ & $(0.70)$ & $(-0.26)$ & $(-1.14)$ & $(0.45)$ & $(-0.35)$ \\
\hline$N$ & 1546 & 1005 & 1237 & 1237 & 1237 & 1237 & 1081 & 1219 & 1546 \\
\hline \hline
\end{tabular}

Note: The table reports the results of a fuzzy RD design. The outcome variables are fundamental firm variables and the dependent variable is an indicator for addition to the Russell 2000 index. The data on fundamental variables is annual so estimates cannot be reported separately for each month. T-statistics are reported in parentheses. All regressions use firms with end-of-May ranking within 100 spots of the predicted cut-off. The regression specification is linear in ranking and is allowed to vary on either side of the cut-off. Only firms that were members of the Russell 1000 index at the end of May are used to estimate the addition effect. Only those that were members of the Russell 2000 are used for the deletion effect. The sample period is $1996-2012$.

$* \mathrm{p}<0.05,{ }^{* *} \mathrm{p}<0.01,{ }^{* * *} \mathrm{p}<0.001$ 
Table 8: Lower Cut-off Returns

Addition Effect

\begin{tabular}{cccccc}
\hline \hline & May & Jun & Jul & Aug & Sep \\
\hline & -0.034 & 0.036 & 0.022 & -0.031 & 0.029 \\
& $(-1.09)$ & $(1.45)$ & $(1.02)$ & $(-1.29)$ & $(1.25)$ \\
\hline$N$ & 822 & 835 & 829 & 823 & 813 \\
\hline \hline
\end{tabular}

Deletion Effect

\begin{tabular}{cccccc}
\hline \hline & May & Jun & Jul & Aug & Sep \\
\hline & 0.015 & 0.033 & $0.058^{*}$ & -0.054 & $0.055^{*}$ \\
& $(0.52)$ & $(1.25)$ & $(1.97)$ & $(-1.82)$ & $(2.00)$ \\
\hline$N$ & 770 & 771 & 766 & 765 & 764 \\
\hline \hline
\end{tabular}

Note: The table reports the results of a fuzzy RD design. The outcome variable is monthly stock returns and the dependent variable is an indicator for addition to the Russell 2000 index. Monthly returns are shown for the month immediately preceding the index rebalancing (June) and for four months after. The instrument for addition is an indicator for firms with ranking 3000 or less. T-statistics are reported in parentheses.All regressions use firms with end-of-May ranking within 100 spots of the predicted cut-off. For both addition and deletion, the RD estimate is shown use both a linear $(\mathrm{p}=1)$ and quadratic $(\mathrm{p}=2)$ polynomial in firm ranking that is allowed to vary on either sides of the cut-off. Only firms that were not members of the Russell 3000 index at the end of May are used to estimate addition. Only those that were members of the Russell 2000 index at the end of May are used to estimate deletion. The sample period is 2005-2012.

${ }^{*} \mathrm{p}<0.05,{ }^{* *} \mathrm{p}<0.01,{ }^{* * *} \mathrm{p}<0.001$ 
Table 9: Lower Cut-off Outcome Variables

Addition Effect

\begin{tabular}{lccccc}
\hline \hline & May & Jun & Jul & Aug & Sep \\
\hline CORR 2000 & 0.009 & 0.029 & $0.250^{* * *}$ & $0.283^{* * *}$ & $0.242^{* * *}$ \\
& $(0.17)$ & $(0.63)$ & $(5.06)$ & $(5.92)$ & $(4.35)$ \\
\hline VOL & -0.001 & 0.005 & 0.002 & 0.005 & 0.003 \\
& $(-0.26)$ & $(1.55)$ & $(0.57)$ & $(1.34)$ & $(0.77)$ \\
\hline ILLIQ & 3.516 & -3.679 & $-23.593^{*}$ & -1.236 & -8.204 \\
& $(0.24)$ & $(-0.60)$ & $(-2.16)$ & $(-0.13)$ & $(-1.08)$ \\
\hline IO & \multicolumn{5}{c}{0.009} \\
& 0.012 & & $0.22)$ \\
\hline VR & -0.750 & $3.332^{* * *}$ & $0.332^{* *}$ & 0.091 & -0.231 \\
& $(-1.86)$ & $(7.02)$ & $(2.91)$ & $(0.62)$ & $(-1.01)$ \\
\hline ISSUANCE & & 0.094 & & & \\
& -0.008 & -0.002 & $0.021^{* *}$ & $0.021^{* *}$ & $0.019^{* *}$ \\
\hline SR & $(-1.16)$ & $(-0.34)$ & $(2.80)$ & $(2.80)$ & $(2.68)$ \\
\hline$N$ & 496 & 502 & 499 & 495 & 489 \\
\hline \hline
\end{tabular}

Deletion Effect

\begin{tabular}{lccccc}
\hline \hline & May & Jun & Jul & Aug & Sep \\
\hline CORR 2000 & -0.006 & 0.061 & $0.181^{* * *}$ & $0.352^{* * *}$ & $0.281^{* * *}$ \\
& $(-0.12)$ & $(1.39)$ & $(3.60)$ & $(6.97)$ & $(5.21)$ \\
\hline VOL & 0.001 & -0.000 & 0.005 & 0.003 & 0.006 \\
& $(0.24)$ & $(-0.08)$ & $(1.20)$ & $(0.76)$ & $(1.48)$ \\
\hline ILLIQ & -5.105 & -0.819 & -0.231 & -1.927 & -4.393 \\
& $(-0.94)$ & $(-0.41)$ & $(-0.13)$ & $(-0.89)$ & $(-1.10)$ \\
\hline IO & & 0.031 & & & 0.041 \\
& -0.093 & $-1.530^{* * *}$ & 0.196 & 0.046 & $(1.04)$ \\
\hline VR & $(-0.78)$ & $(-6.00)$ & $(1.96)$ & $(0.36)$ & $(3.72)$ \\
& & -0.456 & & & \\
\hline ISSUANCE & $(-1.45)$ & & & \\
& -0.005 & -0.002 & $0.020^{* *}$ & $0.021^{* *}$ & $0.018^{* *}$ \\
\hline SR & $(-0.62)$ & $(-0.21)$ & $(2.59)$ & $(2.93)$ & $(2.63)$ \\
\hline$N$ & 581 & 580 & 577 & 575 & 574 \\
\hline \hline
\end{tabular}

Note: The table reports the results of a fuzzy RD design. The dependent variable is an indicator for addition to the Russell 2000 index. T-statistics are reported in parentheses. All regressions use firms with end-of-May ranking within 100 spots of the predicted cut-off. The regression specification is linear in ranking and is allowed to vary on either side of the 3000 cut-off. The instrument for addition is an indicator for firms with ranking 3000 or less. Only firms that were not members of the Russell 3000 index at the end of May are used to estimate the addition effect. Only those that were members of the Russell 2000 are used for the deletion effect. Issuance is defined for the fiscal year. Definitions of fiscal year vary by company but always include the June following reconstitution. The sample period is 2005-2012.

$* \mathrm{p}<0.05,{ }^{* *} \mathrm{p}<0.01, * * * \mathrm{p}<0.001$ 
Table 10: Lower Cut-off Validity Tests

Addition Effect

\begin{tabular}{ccccccccc}
\hline \hline & MKTCAP & REP & ROE & ROA & EPS & ASSETS & ICR & C/A \\
\hline & 0.013 & 0.090 & 0.196 & 0.001 & 0.033 & -43.161 & -159.180 & 0.061 \\
& $(1.44)$ & $(0.78)$ & $(0.84)$ & $(0.02)$ & $(0.11)$ & $(-0.37)$ & $(-1.57)$ & $(1.57)$ \\
\hline$N$ & 837 & 357 & 396 & 396 & 395 & 396 & 315 & 393 \\
\hline \hline
\end{tabular}

Deletion Effect

\begin{tabular}{ccccccccc}
\hline \hline & MKTCAP & REP & ROE & ROA & EPS & ASSETS & ICR & C/A \\
\hline & -0.011 & 0.094 & 0.126 & -0.012 & -0.400 & -49.995 & 24.090 & 0.030 \\
& $(-1.06)$ & $(0.90)$ & $(0.83)$ & $(-0.27)$ & $(-1.14)$ & $(-0.34)$ & $(0.03)$ & $(0.87)$ \\
\hline$N$ & 771 & 458 & 501 & 501 & 500 & 502 & 394 & 494 \\
\hline \hline
\end{tabular}

Note: The table reports the results of a fuzzy RD design. The outcome variables are fundamental firm variables and the dependent variable is an indicator for addition to the Russell 2000 index. The data on fundamental variables is annual so estimates cannot be reported separately for each month. T-statistics are reported in parentheses. All regressions use firms with end-of-May ranking within 100 spots of the predicted cut-off. The regression specification is linear in ranking and is allowed to vary on either side of the 3000 cut-off. The instrument for addition is an indicator for firms with ranking 3000 or less. Only firms that were not members of the Russell 3000 index at the end of May are used to estimate the addition effect. Only those that were members of the Russell 2000 are used for the deletion effect. The sample period is 2005-2012.

${ }^{*} \mathrm{p}<0.05,{ }^{* *} \mathrm{p}<0.01, * * * \mathrm{p}<0.001$ 